\title{
Learning from the Past, Looking to the Future: Modeling Social Unrest in Karachi, Pakistan
}

\author{
JR Olson \\ G Hund \\ AJ Kurzrok \\ EM Fagley
}

January 2014

Pacific Northwest

NATIONAL LABORATORY

Proudly Operated by Battelle Since 1965 


\title{
DISCLAIMER
}

This report was prepared as an account of work sponsored by an agency of the United States Government. Neither the United States Government nor any agency thereof, nor Battelle Memorial Institute, nor any of their employees, makes any warranty, express or implied, or assumes any legal liability or responsibility for the accuracy, completeness, or usefulness of any information, apparatus, product, or process disclosed, or represents that its use would not infringe privately owned rights. Reference herein to any specific commercial product, process, or service by trade name, trademark, manufacturer, or otherwise does not necessarily constitute or imply its endorsement, recommendation, or favoring by the United States Government or any agency thereof, or Battelle Memorial Institute. The views and opinions of authors expressed herein do not necessarily state or reflect those of the United States Government or any agency thereof.

\author{
PACIFIC NORTHWEST NATIONAL LABORATORY \\ operated by \\ BATTELLE \\ for the \\ UNITED STATES DEPARTMENT OF ENERGY \\ under Contract DE-AC05-76RL01830
}

Printed in the United States of America
Available to DOE and DOE contractors from the Office of Scientific and Technical Information,
P.O. Box 62, Oak Ridge, TN 37831-0062;
ph: (865) 576-8401
fax: $(865) 576-5728$
email: reports@adonis.osti.gov

Available to the public from the National Technical Information Service

5301 Shawnee Rd., Alexandria, VA 22312

ph: (800) 553-NTIS (6847)

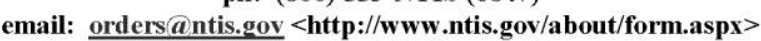

Online ordering: http://www.ntis.gov

This document was printed on recycled paper. 


\title{
Learning from the Past, Looking to the Future: Modeling Social Unrest in Karachi, Pakistan
}

\author{
JR Olson \\ G Hund \\ AJ Kurzrok \\ EM Fagley
}

January 2014

Prepared for

the U.S. Department of Energy

under Contract DE-AC05-76RL01830

Pacific Northwest National Laboratory

Richland, Washington 99352 


\section{Executive Summary}

Social unrest represents a major challenge for policy makers around the globe, as it can quickly escalate from small scale disturbances to highly public protests, riots and even civil war. An initial review of policy whitepapers and national security commentary identified resource scarcity, mega-city growth and climate change as key factors of potential importance to the incidence and consequences of social unrest.. PNNL's Center for Global Security, Global Risk Initiative aims to provide a deeper understanding about the potential implications of these factors on the United States' national security. This interest led to a workshop cohosted by PNNL, the U.S. Institute for Peace and the National Academy of Sciences. At the workshop policymakers from UNDP, USIP and other development agencies discussed the significance of these factors and potential U.S. actions to mitigate the most threatening outcomes. This paper follows policymakers' comments from that workshop that models addressing social unrest and regional climate impacts are generally not helpful to decision-makers, in part because they are not disaggregated to the geographic level at which policy decisions are made. This paper addresses social unrest, which is assumed to impact U.S. national security by its ability to destabilize the affected countries.

Our subsequent investigation found that existing state level models of unrest could be improved in spatial scale to the city level, even without significantly improved data sources. Better data would make this analysis more complete and likely improve the quality of the model. This report describes the work and findings of the project. It took place in three phases: a literature review of social stability research, a "hindsight scan" that looked at historical data, and a "foresight scan" looking at future scenarios.

In the first phase of the project the research team found that recent scholarship on the theory of violent conflict, protest and rioting is resulting in a merging of two early theoretical perspectives. Current theory views individuals as "situated agents" who are forced to make decisions within the constraints of existing societal structures, such as government, social networks and norms. One detailed theory that addresses conflict holistically from this perspective is the theory of Protracted Social Conflict (PSC). PSC notes that structural conditions and individual desires interact and evolve over time in periods of overt and latent conflict, where actions by the participants (the state and individuals) can escalate and de-escalate the situation. Understanding these escalation processes is important to understanding unrest.

In the second phase of the project, the research team sought to understand the key drivers of conflict by operationalizing PSC's qualitative theory using a regression model on data from 1979 to 2008 for the state of Pakistan and the city of Karachi. Downscaling the model to Karachi represents a significant advance in the literature on conflict. The analysis showed that population change and polity type (level of democracy) have had a consistent and significant impact on unrest in Karachi.

The final phase employed the empirical model from phase two to analyze five statistically plausible scenarios for Karachi's future from 2008 to 2030. In agreement with the phase two findings, it notes that periods of high population growth represent the most significant threat for unrest. It also identified shortcomings in the scenario sub-models that could provide an area of future research.

The final recommendations from this report are to pursue a research agenda that focuses on:

1) acquisition of city level data

2) improved models of the effect of natural disaster, specifically the linkages to demographic change due to migration and the impact on economic growth

3) improved models of the dynamics of economic growth

4) improved scenarios, possibly derived from climate assessment models that forecast both economic growth and natural disasters. 


\section{Glossary}

Black Swan - From Taleb (2007), a black swan is a high impact, low probability event that is by definition not included in most forecasts which aim to see the most likely outcome. However, Black Swan events like the terrorist attacks on $9 / 11$ tend to systematically invalidate all previous forecasts and change the course of history.

Conflict - A disagreement between two parties.

Foresight Scan - Term used by the authors to describe the scenario driven case study analysis of Karachi.

Hindsight Scan - Term used by the authors to describe the historical case study using regression analysis of Karachi.

Human Needs - In this analysis, human needs are drawn from Maslow and include Security Needs (basic survival requirements), Access Needs (the need to participate in decision making) and Acceptance Needs (the need to be a part of a group).

Latent Conflict - Conflict that is ongoing, but generally not observable, such as social norms that prevent an ethnic group from having an equal chance at education, among others.

Megacity - Metropolitan area with a population greater than 10 million.

Overt Conflict - Conflict that can be observed, such as protesting, rioting or fighting.

Patterns of Conflict - Actual processes and activities that occur during a conflict that can be either peaceful or violent.

Protest - Periods of peaceful mass mobilization by the public.

Relative Deprivation - From Gurr (1973), absolute deprivation is having less of an item than is needed, but relative deprivation is having less of an item than is wanted. The amount wanted could be conditioned on necessity, but it can also be conditioned on the amount that a neighbor or friend has.

Riot - Periods of violent mass mobilization by the public, including looting, property damage and small scale violence.

Situated Agent - Term of art describing a unit in a model that makes decisions to maximize its benefits while operating within the structural constraints (rules) imposed by society, including proper behavior, legal systems and history, among others.

Structural Factors - Factors that are slow changing and systematically affect a group, such as economic growth. They are specifically out of the direct control of a single agent, but instead set boundary conditions for behavior.

Temporal Dependence - Statistical situation where an observation from one time period is conditioned on an observation in the previous period.

Unrest - Organized social mobilization for protests, riots or violent civil conflict. 



\section{Contents}

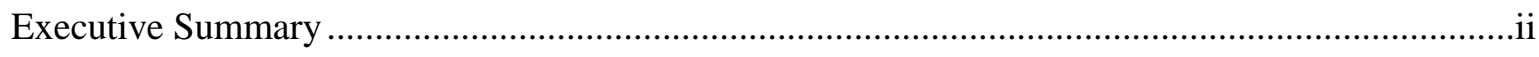

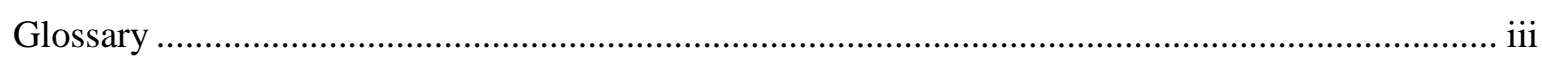

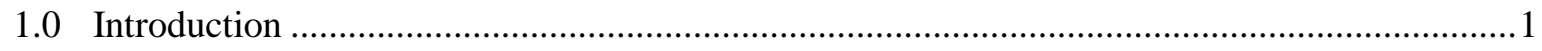

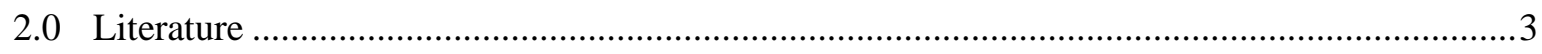

2.1 Protests, Riots and Violent Conflict .......................................................................... 3

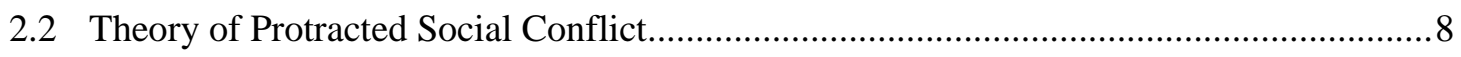

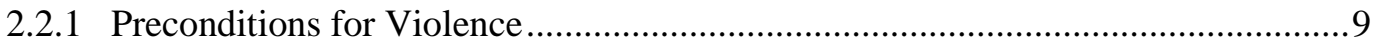

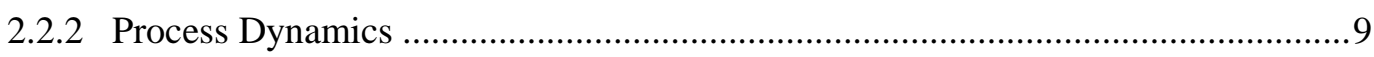

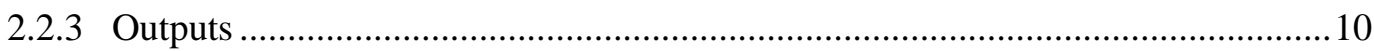

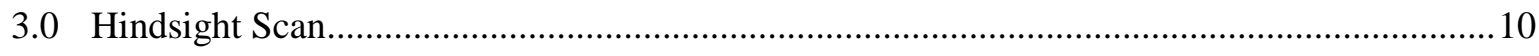

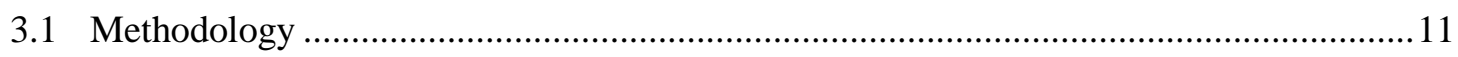

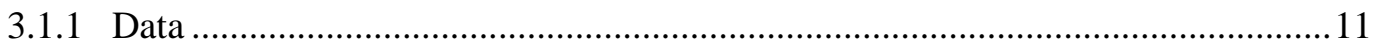

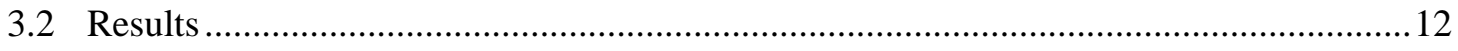

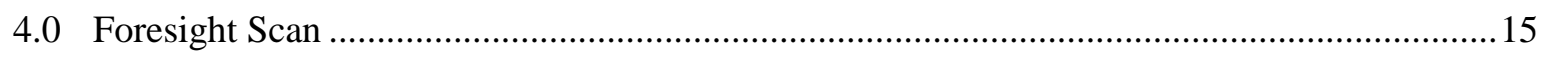

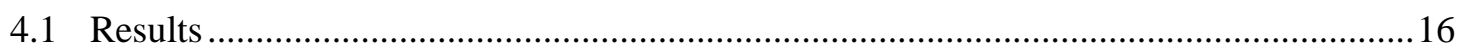

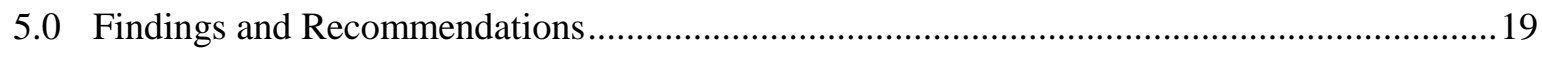

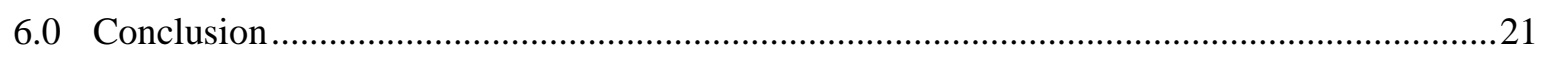

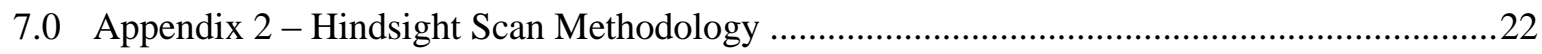

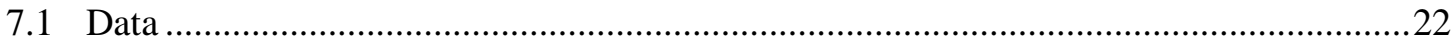

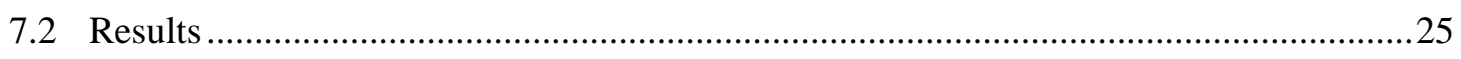

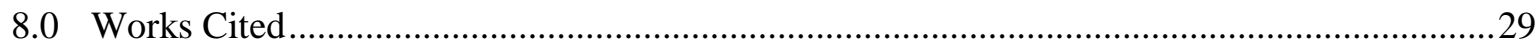




\section{Figures}

Figure 1 - Global Risk Initiative Analytical Framework..............................................................

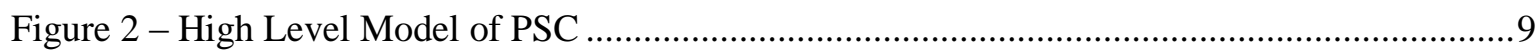

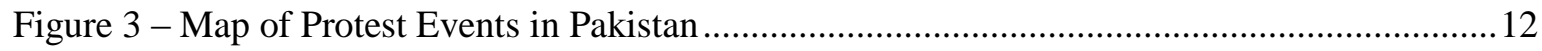

Figure 4 - Map of Protest Events in Karachi ........................................................................... 12

Figure 5 - Predicted Count vs. Actual - Protests ....................................................................... 14

Figure 6 - Predicted Count Vs. Actual - Riots .......................................................................... 14

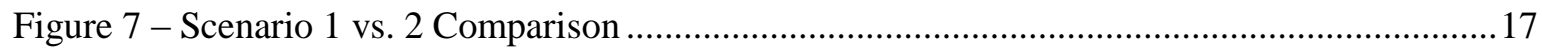

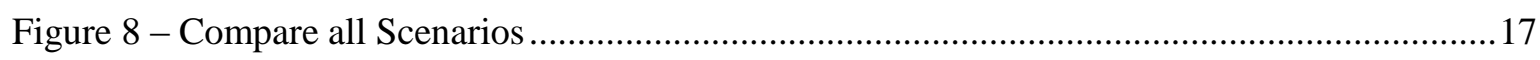

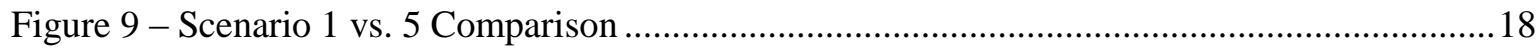

Figure 10 - Scenario 6 Black Swans ..................................................................................... 19

Figure 11 - Map of Protest Events in Pakistan .........................................................................23

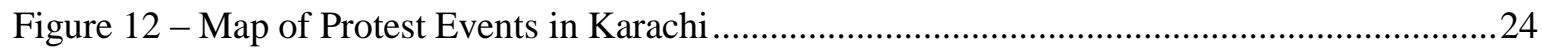

Figure 13 - Predicted Protests per Year..............................................................................2

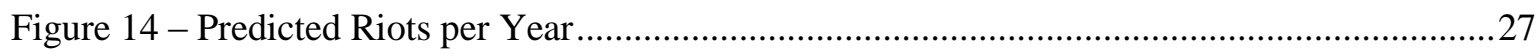

Figure 15 - Predicted Count vs. Actual - Protests......................................................................28

Figure 16 - Predicted Count Vs. Actual - Riots ...................................................................28 


\section{Tables}

Table 1 - Top variables tested in empirical quantitative violent conflict literature.........................6

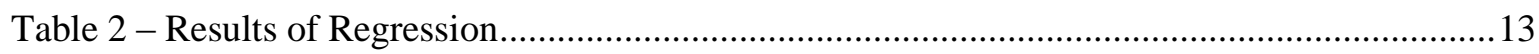

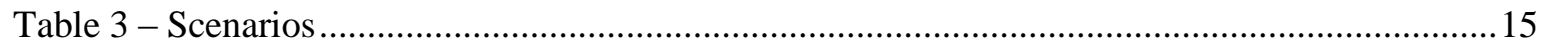

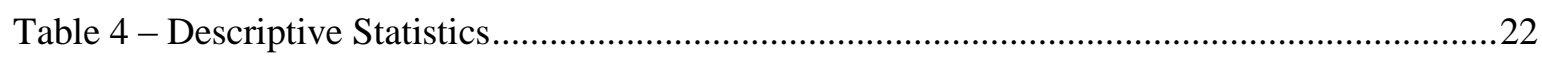

Table 5 - Regression Results, Protests and Riots ...................................................................26 


\subsection{Introduction}

Social unrest ${ }^{1}$ represents a clear and ongoing challenge for policy makers that can manifest itself in protests (e.g. Istanbul, 2013), rioting (e.g. London, 2011) and civil war (e.g. Syria, 2011-2013). Analysts expect multidimensional pressures on megacities to significantly affect local and state stability and pose strategic challenges to the global economy and other interests (NIC, 2013). The Arab Spring is a great example the consequences of those pressures and showed the vulnerability of some governments to social unrest and eventually led to the collapse of the government in Egypt and Tunisia. But what are the systematic vulnerabilities that led to the overthrows? Proposed answers in the Tunisian context range from hunger (IFPRI, 2013), to social injustice (Ryan, 2011), but academics are uncertain and have struggled to answer this question definitively. Adding to the uncertainty for policymakers, climate change holds the potential to dramatically change the vulnerability to hazards and the ability of the international community to respond to crises. As the potential for climate change impacts grows and megacities expand, there is a growing need for better understanding and interpretation of the triggers of social unrest.

Policymakers benefit from understanding and planning for social unrest because of its potential to disrupt development and jeopardize security. At a domestic level, major unrest poses a direct threat to plan implementation, economic development and law and order. At the international level, unrest can threaten key economic and security interests and can lead to major humanitarian crises. Analysts, including the National Intelligence Council, have argued that over the next 10-20 years, trends in technology, demography, politics, economics and culture will reshape the issues that the international community, and consequently the United States, will confront (National Intelligence Council, 2013). The Global Risk Initiative of the Pacific Northwest National Laboratory's Center for Global Security aims to provide a deeper understanding of the implications of these trends on the United States. An initial review of potentially pertinent trends identified resource scarcity, mega-city growth and climate change as key topics of interest. One objective of the workshop the center co-hosted with the U.S. Institute for Peace and National Academy of Sciences with policymakers from UNDP, USIP and other development agencies was to discuss the significance of these trends and potential U.S. actions to mitigate the most threatening outcomes predicted by the trends. The workshop participants concluded that existing regional models of climate change and unrest were insufficient for the users and that an objective of the Global Risk Initiative should be to close this gap and help bring scientific support to the policy decision environment.

To help guide the development of a research agenda focused on long-term threats to U.S. national security, the research team developed an analytical framework for the Global Risk Initiative, shown below. The arrows represent hypothesized relationships between key topics of interest, represented by the boxes. The framework is intended to articulate assumptions about the initiative's relationship to national security. The box, "Other Hypothesized Threats," allows for the inclusion of other hypothesized threats, such as global terrorism. This analysis addresses boxes 1, 2 and 3. It assumes the relationships between boxes 4, 5 and 6 exist, but does not test or attempt to characterize these relationships. Other authors on the topic of revolution like Theda Skocpol and Jack Goldstone have considered the relationship between box 4 and 6, but that is outside the scope of this research project.

\footnotetext{
${ }^{1}$ For the purpose of this paper, social unrest is defined as organized social mobilization for protests, riots or violent civil conflict. Protests are periods of peaceful mass mobilization by the public, whereas riots involve looting, property damage and small scale violence. For the definition of civil war, we defer to the literature which defines it as 25 or more battle-related deaths in a given year in a given country (Gleditsch, Wallensteen, Eriksson, Sollenberg, \& Strand, 2002).
} 


\section{Global Risk Initiative Analytical Framework}

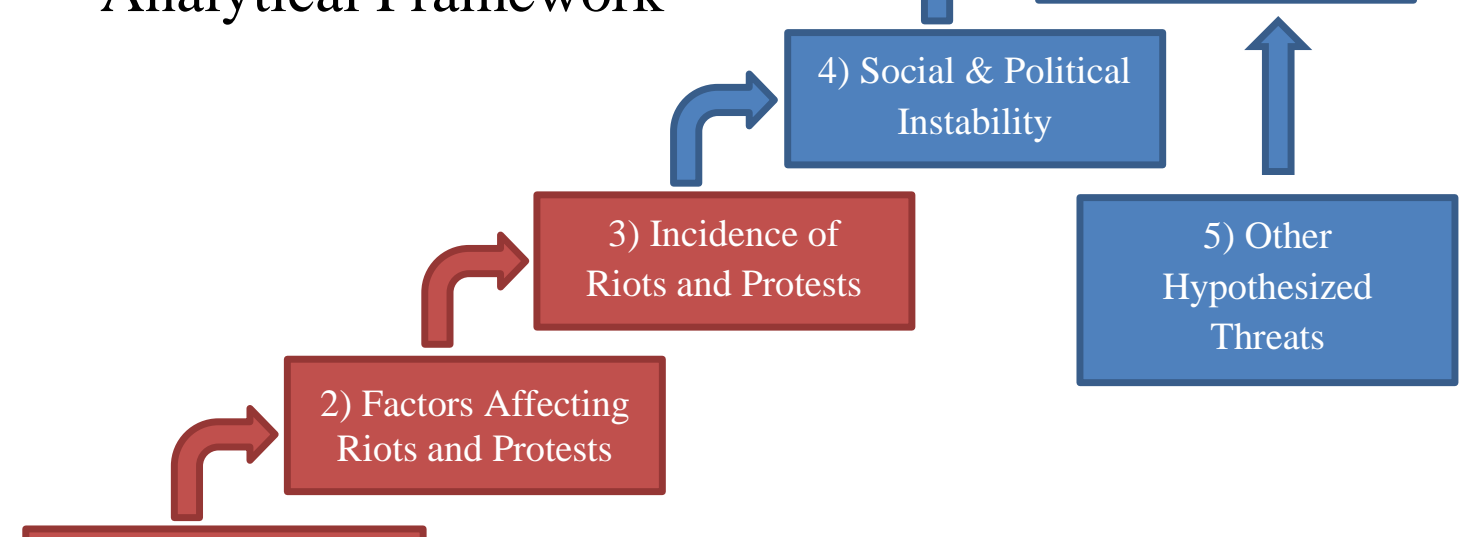

1) Scarcity, Climate

Change, Mega-Cities

Figure 1 - Global Risk Initiative Analytical Framework

Considerable work has been done academically to model and forecast social unrest and its precursors, but the geographic scope of these studies tends to be either a small area (neighborhood, town square, etc.) or the state level ${ }^{1}$ and they do not address questions of climate change or other forward-looking systematic changes. This effort employs Azar's (1990) theory of Protracted Social Conflict (PSC) in a historical analysis, hereafter referred to as a "hindsight scan," and a forward looking scenario analysis, hereafter referred to as a "foresight scan," of one of the ten largest cities in the world, Karachi, Pakistan. The hindsight scan employs a quantitative model of city level unrest derived from PSC covering the time period from 1979 to 2008 and models the relationships shown in boxes 2 and 3 from Figure 1. The results suggest that city-level modeling is possible, but that access to data at a smaller spatial scale would likely improve modeling efforts. We identify population growth as the most significant driver of protest in the past, with the affect much larger in Karachi than in Pakistan. Additionally, we found that a higher level of democracy in Pakistan significantly decreases the number of protests in Karachi. This analysis also includes a foresight scan to understand the likely impacts of a series of statistically reasonable scenarios on social unrest in Karachi, which allowed for an analysis of the anticipated effects of the factors included in box 1 of figure 1 . The results indicate that nearly all the change in social unrest is driven by the dynamics of population change, but the project team recommends future research to improve the submodels employed in the scenario analysis to better understand the role of natural disasters in social unrest. This report details the results of a literature review on social unrest and the Theory of Protracted Social Conflict in the background section, discusses the approach and findings from the hindsight scan and the foresight scan and then discusses the findings and recommendations for future research.

\footnotetext{
${ }^{1}$ Note: For the purposes of this article, "State" refers to a geographically bounded area under the control of a central government, synonymous with "country."
} 


\subsection{Literature}

To build a better understanding of the existing literature on social unrest, the project team performed two literature searches. The first examined theories of protests, riots and violent conflict and suggested that a generalized theory of "conflict" based on Edward Azar's theory of Protracted Social Conflict could be a useful starting point for modeling protest and riot quantitatively. The second literature review examined PSC in greater detail. This literature review describes the findings for both reviews.

\subsection{Protests, Riots and Violent Conflict}

Social unrest is defined in this paper as periods of major turmoil in a social system. It includes social mobilization for mass protest or riot and violent conflict. This provides a starting typology for analysis of the topic. One factor in common among these is "conflict," which Azar (1990) defines as a disagreement between two or more parties. Conflict coping mechanisms can lead to stable outcomes or destabilize the system. The focus of this review is the latter, in which a conflict evolves into protests, riots or violent conflict.

Papers were gathered from searches of several databases (Google Scholar, Microsoft Academic, and Summit Scholars Archive). Existing academic literature reviews on theoretical topics or modeling trends were prioritized and employed where possible. Documents discovered via databases were used to identify additional key sources.

Underlying theories regarding the causes of conflict were noted and categorized based on the role of human agency ${ }^{1}$. Structural models look at stable, relatively unchanging features of the environment, society or government that assume individuals have no human agency and simply react to their surroundings. Individual Motivational models look at the individual's desire to maximize utility and always assume rationality of the agent. These categories are viewed as a continuum, with models that explicitly consider interactions between structure and motivation labeled "Hybrid" theories.

\section{Protest}

For the purpose of this paper, protest is an action of collective mobilization against a government that is not violent or destructive of property. The literature on this topic typically draws from sociology and theories of social mobilization. Crossley (2002) notes that social mobilization theories can be separated by both time and space. While Europeans tend to focus on the meaning and perception of a protest, the American tradition is much more interested in understanding who protested and why the protest happened where and when it did. Both fields underwent considerable change during the 1960s in an effort to adapt to the rapidly changing protest environment. Whereas before 1960, academics viewed protestors (especially in the United States) as marginalized youth behaving irrationally, following the 1960s, a more instrumental rational model of the protestor evolved.

The earlier theories revolved around Olson's (Olson M. , 1965) economic theory of collective action, where social mobilization was constrained by the free-rider problem. It said that protesters could not be rational actors, because benefits from social mobilization do not accrue to the individual, so the incentive to protest is reduced and rational people will fail to act. It also requires that a grievance, Durkheim's anomie, exist in order for leaders to rally a group to protest that grievance. In other words, this theory only allows for protest when rational leadership is able to rally individuals around a group emotion and

\footnotetext{
${ }^{1}$ Human agency refers to the ability (agency) of an individual to have an effect on their life. No human agency is fatalistic, whereas pure human agency assumes no influence by outside actors.
} 
move a protest forward. Accordingly, the "who, what, when and why" of protests is conditional on the leadership of protests.

After the 1960s, empirical evidence suggested that irrationality was not a sufficient explanatory factor for protest. Data showed that protest often involved well-educated individuals with strong moral or personal grievances. It also showed that protest was frequently driven at a grass-roots level, as compared to the conception of action due to strong leadership (Crossley, 2002). Out of this disjuncture with the Theory of Collective Action came the Resource Mobilization Theory. Under Resource Mobilization Theory, actors are purely rational and pursue an outcome of their definition. It focuses on an individual's cost-benefit analysis and requires analysts to think in terms of inputs (actors) and outputs (change). This approach discards the structural component of theory and leans more on an Individual Motivational approach.

Resource Mobilization Theory employs a naïve cost-benefit analysis because it does not incorporate the likelihood of success into the analysis. To address this shortcoming, the Political Processes hypothesis grew out of the Resource Mobilization Theory tradition and argued that the likelihood of protest depended on the likelihood of success in a non-linear way (Tilly, 1978). In effect, as a society moves away from zero political opportunity, protest will become more likely because the costs of participating will go down. At some point, there will be diminishing absolute returns and protest will decline. In other words, a situated agent is constrained by the structure of society and makes choices to maximize its benefit in that context. Meyer (2004) argues that it is important to understand that openness has a variety of impacts on different groups. For the mainstream population, protests may increase with any opening in opportunity, whereas marginalized groups may not protest until a certain threshold of openness has passed. Additionally, Meyer (2004) notes a fundamental tradeoff between the probability of policy change and the probability of mobilization because the ability to make political change undercuts the need for mobilization.

The empirical work on protest is frequently case study based, where data exists about participation in a single protest event and hypothesis tests are constrained to components of a social mobilization theory. Within the political processes tradition, work tends to focus on structural, exogenous features that affect a movement's prospect for mobilizing, advancing claims over others, cultivating alliances, employing certain strategies, and affecting mainstream policies (Meyer, 2004). One example from this tradition draws heavily on collective action theory and an individualist approach. It employed a panel survey of participants in the protests against communism in East Germany. Opp and Kittel (2010) found that crosssectional data analysis approaches commonly employed by researchers, failed to capture the endogeneity of some independent factors at the individual level, such as the perception of ability to change an outcome. This study found support for structural factors that increase or dampen protest and argues that democratic regimes will have more protest because opportunity is higher and costs are lower. One effect of the narrow, case-based approach has been a lack of macro-theory development. However, Oliver (2003) notes that empirical work has adjusted in the last two decades, is developing broader theories that apply outside of Europe and the U.S. and take a more systematic view. These studies require a broader empirical context, because access to pure panel data on individual perspectives is costly and difficult to acquire. It is possible that this transition may be driving the renewed interest in the political process tradition, which focuses on individual behavior within a structured environment.

\section{Riots}

A riot is a form of social unrest that is defined as an abrupt and intense rash of violence against authority, property or people. Similar to protests, popular literature draws on theories of social mobilization and collective action; however, riots are one of the least understood elements of social unrest. Scholars often focus on the structural socio-economic conditions to identify the cause. While poverty, inequality, ethnic tensions, unemployment, and age demographics do play a role, some scholars (e.g. Cavanagh and Dennis, 
2012; Gross, 2011) seek to move away from a structuralist approach towards a more individualist and hybrid approach to understand why riots happen, why people get involved, and where riots happen.

Cavanagh and Dennis (2012) take an explanatory approach of showing how media and politics were influential factors that drove public perceptions by comparing riots from 1981 to the 2011 riots. This reflects the European social unrest research tradition by focusing on how the riots were labeled and the meaning attributed to them in popular press. In their findings, media reports from 1981 found deprivation and social problems to be the cause, but that the 2011 riots were seen as contagious and random where a mob of disgruntled, disorganized youth with no motive carried out criminal acts (Cavanagh \& Dennis, 2012). This reflects an ontological shift in the popular literature back towards Olson's (1965) theory of Collective Action, which the academic literature has moved away from in favor of Resource Mobilization theories. According to Cavanagh and Dennis, Resource Mobilization more accurately explains the behavior of individuals (Cavanagh \& Dennis, 2012). They highlight three indicators supporting a rational interpretation of individual behaviors including a process of escalating disdain towards police, socially motivated looting of valuable goods from large chain stores, and a mapping of rioting behavior that predicted presence of riots where police presence was lowest (Cavanagh \& Dennis, 2012). This disjuncture in the popular and the academic literature suggests a potential gap in understanding of the causes of riots that could affect policymaking.

The biological or process-based approach to explaining and predicting riots looks to understand the "mechanism of infection" for how violence spreads and to explain sudden shifts in individual behavior (Gross, 2011) The concept of herding looks at how an individual draws on information about the choices others make in the absence of information and is considered a rational behavior by many in economics (Baddeley, 2009). Connecting this to the London 2011 riots, Gross argues people who normally avoid involvement, suddenly made a decision to join based on the decisions of others (Gross, 2011). Raafat, Charter and Frith (2009) examine herding as a convergent behavior in a group through local interaction and without centralized coordination. In their analysis, Raafat et al. used diffusion theory to explore social networks and its role in influencing the spread of ideas and practices (Raafat, Chater, \& Frith, 2009). The biological or process-based approach is promising but there are still holes in the research. For example, the emotional capacity of an individual is difficult to analyze - especially when examining how the transmission of emotions occurs. In addition, there is considerable uncertainty due to technology. With the level of information sharing today, there are more points of contact that could contribute to herding behavior and function as an accelerant.

A geographical approach to studying riots tends to employ structural explanations of rioting by focusing on the environment and location of events. Philips et al. (2013), also argue there is a geographical shift of riot location as inner cities are no longer an epicenter for conflict. Further, current mapping often relies on structural conditions even though it fails to show "causality between deprivation and the propensity to riot" (Philips, Frost, \& Singelton, 2013). Till (2012) notes that geographic explanations use outdated theories like spatial determinism to understand riots, which he argues was undermined by the 2011 London Riots, which was not centered around structurally challenged areas, but instead on the periphery. He assumes that institutionalized inequality was a key driver, but offers no evidence to support this claim. To counter these shortcomings in theory, Philips et al. (2013) recommends a research strategy to improve the robustness of geographical approaches that employs regression models for comparison of areas with social unrest against areas without social unrest. Furthermore, they argue that a qualitative understanding of rioter feelings is important to understand patterns of behavior and types of grievances (Philips, Frost, \& Singelton, 2013).

One comparative study from the geography tradition presents a hybrid perspective, where poverty makes a population more vulnerable to manipulation and control by leaders with bad intentions. This theory blends structure (poverty) and individualism (leadership rationality). Empirically, Berenschot (2010) 
compares spatial distribution between two neighborhoods in Gujarat, India. In one neighborhood, violent rioting erupted, whereas in the other it did not. In a qualitative analysis, he found that in the neighborhood of Isanpur, where violence erupted, the patronage network was hierarchical and competitive, whereas in Raamrahimnagar, the patronage network was more distributed and cooperative (Berenschot, 2010). This study makes key structural assumptions about poverty as a cause of violent rioting, but fails to defend that assumption. However, its treatment of leadership rationality implies some theoretical sophistication and development towards an interactive, hybrid model.

\section{Violent Conflict}

Violent conflict, defined as periods of government vs. civilian conflict resulting in more than 25 deaths in a given year, has motivated academic study for centuries, but since the late 1990s, quantitative empirical research has surged. Unfortunately, it has not led to an improved understanding in the causes of conflict with results that contradict as much as they confirm (See Table 1). Dixon (2009) highlighted this as a major weakness in the literature and attributes it to the use of kitchen-sink regression models with little consideration for theory. Theories of violent conflict have also suffered from this lack of integration with empirical research. Most quantitative empirical models build on one of two theoretical models from early in the development of quantitative research.

Table 1 - Top variables tested in empirical quantitative violent conflict literature

\begin{tabular}{|c|c|c|c|}
\hline Variable & Sum Of Effects & N Models & Avg. Effect \\
\hline Per-capita GDP & -41 & 67 & -0.612 \\
\hline Ethno-linguistic fractionalization & 11 & 60 & 0.183 \\
\hline Democracy & -3 & 49 & -0.061 \\
\hline Population & 24 & 36 & 0.667 \\
\hline Mountains & 18 & 35 & 0.514 \\
\hline Recent Regime Change & 21 & 34 & 0.618 \\
\hline Oil Exporter & 21 & 33 & 0.636 \\
\hline Peace Years & -13 & 33 & -0.394 \\
\hline Polity Score & 3 & 33 & 0.091 \\
\hline Religious Fragmentation & -1 & 27 & -0.037 \\
\hline Primary Commodity Exports & 1 & 25 & 0.04 \\
\hline Anocracy or Semi-Democracy & 12 & 21 & 0.571 \\
\hline New State & 12 & 19 & 0.632 \\
\hline GDP Growth & -8 & 16 & -0.5 \\
\hline Previous War Since 1945 & -4 & 16 & -0.25 \\
\hline Noncontiguous State & 8 & 15 & 0.533 \\
\hline Per-Capita GDP Growth & -8 & 14 & -0.571 \\
\hline Population Density & 6 & 11 & 0.545 \\
\hline Ethnic Heterogeneity & 7 & 10 & 0.7 \\
\hline Rainfall Deviation & 2 & 10 & 0.2 \\
\hline \multicolumn{4}{|c|}{$\begin{array}{l}\text { (1) Variables studied more } 10 \text { times or more in the literature. } \\
\text { (2) "Sum of Effects" assigns a value of }-1 \text { for negative significant findings, }+1 \text { for positive } \\
\text { significant findings and } 0 \text { for insignificant findings. } \\
\text { (3) "Avg. Effect" is the Sum of Effect divided by Count } \\
\text { Sources: Dixon, 2007; Authors own review of literature from 2007-2012 }\end{array}$} \\
\hline
\end{tabular}

Collier and Hoeffler (2004) represent the rationalist, individual theory of conflict where actors are motivated by a calculation of costs and benefits. Hirschleifer (1995) argued that the poor are more inclined towards violent conflict because their future opportunities (earnings, education, etc.) are low enough to warrant the risk of dying in battle. Collier and Hoeffler (2004) argued that a large payoff was necessary to offset the risk of death, which yields no expected future earnings and tied this to the resource curse. Dozens of authors have tested hypotheses based on this fundamental theoretical understanding. This perspective is more common among economists studying violent conflict. Criticism of this theory 
tends to focus on the use of GDP per capita to identify individual cost-benefit approaches. Because it is an aggregate measure, it may not capture important variation among rebels (Cramer, 2002).

Alternatively, Fearon and Laitin (2003) argue from the structuralist perspective that violent conflict is a function of the structural features of society and that individuals do not have the agency to choose conflict. Instead, the authors assume pre-destination due to relatively stable features of society that make conflict more likely. In later work, Collier, Hoeffler and Roehner (2008) call this the feasibility hypothesis, where people fight where it is easiest due to mountainous terrain, weak governments and the availability of resources to sustain war. Structural theories of violent conflict include ethnic conflict (Horowitz, 1985), which has largely failed under empirical evaluation (Fearon \& Laitin, 2003; Fearon J. D., 2005).

This description of the individualist-structuralist divide are exaggerated for illustration, structural factors and individualist factors are frequently included as control variables in models, but are rarely considered from a more hybrid theoretical view, where actors are "situated agents" (Demmers, 2012) making utility maximizing decisions under structural constraints. Gurr (1970) noted the importance of hybridization all the way back in 1973 when he discussed the mostly individualist theory of Relative Deprivation (RD). He argues that people fight when they feel deprived, relative to their previous status or their neighbors. This interpretation relies on both structural (poverty, inequality, economic growth) and individualist issues (personal wealth, access to education). However, this theory fails to address another criticism of causal models of conflict that do not address the pathways towards conflict (Cramer, 2002).

Understanding the causes of conflict and pathways to conflict necessitates an acceptance that seemingly random events quickly devolve from an equilibrium point of stability to violence. Edward Azar (1990) dubbed this the theory of Protracted Social Conflict (PSC). Protracted Social Conflicts are characterized by periods of seeming peace punctuated by periods of explicit violence that never formally conclude as conflicts. Instead, they transition to periods of structural violence that perpetuate the structural underpinnings of violent conflict, awaiting the start of another period of explicit violence by social groups that are relatively deprived of their human needs. Azar explicitly describes these pathways through conflict coping mechanisms and other escalation factors. Conflict coping mechanisms highlight the state and communal actions and any history or structural proclivity of a social group to violent conflict as opposed to peaceful resolution. Escalation factors are easy to identify post facto, but are more difficult to forecast. These include factors like actor and issue spillover or fear of marginalization.

In the specific context of climate change and natural resource scarcity, the natural resource conflict literature tends to take an individualist perspective, where people fight over lootable resources in order to increase the payoff of a victory. However, that theory has found little support in empirical work (Ross, 2004). Qualitative work from Kahl (2006) suggests that a hybrid approach linking relative deprivation to individuals and structural features like weak governments and high degrees of groupness (making formation of rebel groups easier) might yield conflict due to resource deprivation. Kahl notes key contradictions in the natural resource conflict literature due to the individualist vs. structural debate and atheoretical modeling approaches. Looking at the scarcity of food, theorists argue that poorly functioning governments interact with deprivation of food to drive violent conflict (Messer, 2009; Patel \& McMichael, 2009), but the empirical evidence does not support this (Pinstrup-Andersen \& Shimokawa, 2008; Bazzi \& Blattman, 2011; Olson J. , 2013). These analyses have not examined interaction and also suffer from measurement challenges. Other research looking at scarcity of water supports the hybrid theoretical approach, but is also inconclusive (Bernauer, Bohmelt, \& Koubi, 2012).

In a similar challenge to intuition, research into the risk of violent conflict in the context of natural disasters suggests that risk decreases in the time following a natural disaster, possibly, because the disaster binds actors through the necessity of survival (Bernauer, Bohmelt, \& Koubi, 2012). However, 
these studies have not typically looked at the long-range, difficult to quantify impacts on structural drivers of violent conflict caused by major natural disasters or shortages of natural resources like food, land and water. These intermediate needs may be a major risk factor for violent conflict in the future by reducing the capacity of a society to develop economically, which is consistent with existing quantitative models.

The literature on different types of social unrest exhibits some key theoretical similarities suggesting that an overarching model of unrest is attainable. The conflict literature helps to identify some key trends in the theoretical tradition of "conflict," which has applications in all social unrest. Azar (1990) defines a conflict as a disagreement over something and violent civil conflict is a more extreme instance of disagreement. Protests and riots are less extreme reactions. The literature on violent conflict tends to focus on macro-scale and hopes to find generalizable findings, whereas the literature on protests and riots typically uses case studies to examine narrowly scoped occurrences of protest or riot. Our review of the literature found that theoretical literature is moving toward a hybrid model of conflict, where an individual's actions, which are driven by wants and needs, are balanced by the structural constraints of his or her society. Demmers' (2012) "situated agent" can be seen in the violent conflict literature from the Theory of Protracted Social Conflict (Azar, 1990), in the protest literature as the Political Process Hypothesis in the Resource Mobilization tradition (Meyer, 2004) and in the riot literature with theories that reflect a biological understanding of evolving mobilization from protest to riot (Gross, 2011). The interest in generalizable findings make the theories of violent conflict consistent with this project's objective of understanding and modeling generalized indicators of social unrest and they conceptually fit with protests and riots. Accordingly, we employ the Theory of Protracted Social Conflict to explain the causes of protest and riots in this analysis. This review of the literature details the Theory of Protracted Social Conflict.

\subsection{Theory of Protracted Social Conflict}

Azar's PSC theory addresses the root causes of conflict within a state and how patterns of conflict interact with the satisfaction of human needs, the adequacy of political and economic institutions and the choices made by political actors (Miall, 2004). Patterns of conflict are the actual processes and activities that occur during a conflict. These patterns can be peaceful or violent, but play a role on the way the conflict evolves. Protracted Social Conflicts are characterized by periods of seeming peace punctuated by periods of explicit violence that do not have a formal start (e.g. a declaration of war) or end point (e.g. a treaty). Instead, they transition from periods of structural violence, where groups suffer implicit harm like discrimination or increased poverty, to periods of explicit violence, where groups suffer physical harm, like beatings, murder, war and other forms of explicit violence. The structural violence perpetuates the structural underpinnings of violent conflict. The theory focuses on relative deprivation of human need as an indicator of structural violence, which occasionally erupts into explicit violence. It primarily focuses at the state level of analysis (Pfaffenberger, 1994; Leventis \& Tsokkalides, 2007; Bar-Tal, 2009; Piya, 2009). These factors are not necessarily relevant only at the state level, but may also apply at higher or lower (for example, city) levels. Azar highlights three elements: preconditions for violence, dynamic processes and outcomes. Figure 2 shows the basic concept of how these elements interact within the theory and in some cases lead to periods of explicit conflict within a state of protracted conflict. We argue that Protracted Social Conflict is more of a process than a category. Consistent with early work on protest, as a society becomes freer and less authoritarian, different groups begin to agitate for change (Meyer, 2004). Even though in some places the severity of Protracted Social Conflict may be lower (e.g. in Sweden), structural violence still has the potential to exist and in different circumstances may manifest itself in a more explicit manner with protests or riots. However, the severity of response is likely to be different, thus the patterns of conflict may evolve either away from or towards overt conflict. Azar's work was originally intended as a descriptive framework and no quantitative models have been published in the 
peer-reviewed literature. However, the qualitative literature on Azar's work is quite rich and some findings are discussed here as we explore the theory in greater detail.

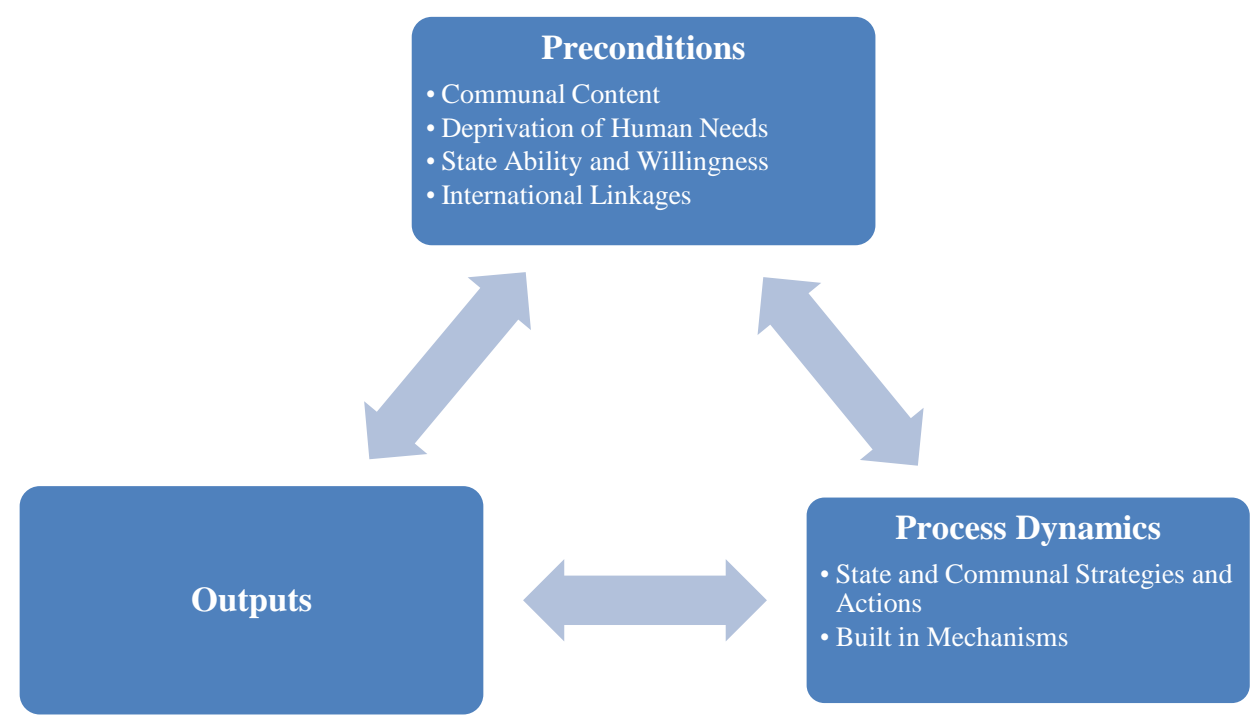

Figure 2 - High Level Model of PSC

\subsubsection{Preconditions for Violence}

In Azar's model, four clusters of preconditions determine the likelihood of conflict: communal content, human needs, the state's role and international linkages (Azar, 1990). Communal content refers to the existence and composition of identity groups that differ in race, religion, ethnicity, and culture. An environment of inequality and deep-rooted hatred can be created through historical rivalries where one group attempts to dominant another or from divide-and-rule policies instituted by former colonial powers (Azar, 1990; Leventis \& Tsokkalides, 2007; Hadjipavlou, 2007; Pfaffenberger, 1994; Piya, 2009; Rakodi, 2012). As for deprivation of human needs, Azar argues that individuals strive to fulfill their needs by working with their collective identity group. These needs, reflecting Maslow's hierarchy of needs, include political access needs, security and resource needs and acceptance needs. Deprivation of these needs results in increased grievances, which individuals express collectively with their identity group (Azar, 1990; Doucey, 2011; Piya, 2009; Pfaffenberger, 1994; Leventis \& Tsokkalides, 2007; Rakodi, 2012). This does not mean violence is inevitable; however denial of access by the state increases the likelihood of overt violence (Azar, 1990; Piya, 2009; Hadjipavlou, 2007; Pfaffenberger, 1994; Leventis \& Tsokkalides, 2007). In a PSC environment, less stable and fragile states' political authority 'tends to be monopolized by the dominant identity group or a coalition of hegemonic groups' (Azar, 1990; Bollens, 1999). Finally, international linkages can be a root cause for violence because political leaders in most PSCs are economically and militarily dependent on richer and stronger states. Such dependence impacts foreign and domestic policies and may disjoin from or contradict the needs of the public (Azar, 1990; Hadjipavlou, 2007; Leventis \& Tsokkalides, 2007; Pfaffenberger, 1994; Piya, 2009).

\subsubsection{Process Dynamics}


The existence of these preconditions does not guarantee that overt conflict will occur (Azar, 1990). ${ }^{1}$ To shift from a latent to an overt phase, Azar identifies three 'activation' variables whose interactive affects can trigger open violence. ${ }^{2}$ These three variables are also known as the 'process dynamics' and include: "communal actions and strategies," "state actions and strategies," and "built-in mechanisms." Communal actions and strategies are decisions a communal group makes as a result of the preconditions already discussed. Such decisions can take the form of a peaceful demonstration and protest to violent action. On the other hand, state actions and strategies are represented by governing individuals and elites, who are also faced with an array of policy choices that range from coercive repression to accommodation. Weak and fragile states, in particular tend to react to communal grievances through coercive repression or instrumental co-option to avoid showing signs of weakness or ceding political power (Azar, 1990). Finally, there are self-reinforcing built-in mechanisms that have a lasting effect on people's perceptions of the state's ability and desire to resolve conflict as well as perceptions between communal groups. In a PSC environment, negative attitudes, perceptions, belief systems and stereotypes become established to a point that these emotive feelings perpetuate communal antagonisms and solidify PSC even among actors not affected by the initial event (Azar, 1990; Musallam, Coleman, \& Nowak, 2007; Zartman, 2005). Violent behavior is viewed as a viable means of interacting with one's counterpart and over time becomes an expected and even functional pattern of behavior making an alternative course (e.g. conflict resolution) of action increasingly unlikely (Gray, Coleman, \& Putnam, 2007).

\subsubsection{Outputs}

Azar's third element looks at the outcomes of overt violence in order to better understand whether and why conflict is resolved and replaced by lasting peace, or is reinforced and becomes protracted (Rakodi, 2012). Azar identifies four aspects of the outcomes, which if negative, perpetuate conflict and increase the likelihood of further violence. In particular, the deterioration of physical security, state incapacity, deeprooted fear and animosity, and economic, political and military dependency on a third party, represent factors associated with future episodic violence. In the end, PSC can become the culture of the state as a sense of hopelessness builds within the population and becomes entrenched as it has in Cyprus. In these circumstances, there is no clear end-point, no clear winner and no avenue to create constructive solutions (Azar, 1990).

\subsection{Hindsight Scan}

Karachi, Pakistan is one of the largest cities in the world, and it faces a variety of security challenges as it continues to grow rapidly. It represents over half of Pakistan's economic production and is home to an estimated 14.5 million people excluding surrounding suburban areas. ${ }^{3}$ It was selected for analysis because its status as a seaport, population size and distance from Islamabad, the capital of Pakistan, makes it crucial to Pakistan's economy and challenging to provide government services. Moreover, data suggest that a large number of documented protests and riots have occurred in Karachi from 1979 and 2013, making it a useful subject statistically because of the variation in the dependent variable (Leetaru \& Schrodt, 2013). To understand the risks of social unrest facing Karachi, we performed a hindsight scan to understand what has happened and to inform our analysis of what could happen in the future. We built on the frameworks discussed with heavy reliance on the theory of PSC, to develop a quantitative model of protests and riots in Karachi and Pakistan from 1979 to 2008. Since PSC was originally designed for state

\footnotetext{
${ }^{1}$ Overt conflict is openly visible and not concealed.

${ }^{2}$ Latent conflict is rooted in longstanding economic inequality, or in groups' unequal access to political power.

${ }^{3}$ Karachi Chamber of Commerce Website, http://www.kcci.com.pk/MyKarachi/AboutKarachi.aspx, accessed September 2013. Note: This is the definition provided by the data-source, referring to the core area of Karachi, and excluding sprawl that is not technically part of the core population of Karachi.
} 
level analysis and efforts have been limited at the city level, the model is first built and validated against state level data to ensure that PSC is a reasonable model for protests. Once this was confirmed, the model was then applied against mixed data from the city of Karachi and data from the state of Pakistan. This section introduces the high level details of the modeling methodology (technical details are available in Appendix II). It then covers the findings from the model.

\subsection{Methodology}

This section provides an overview of the modeling approach. Technical details are available in Appendix II) The model employs a time-series analysis using a special type of Poisson regression called the Negative Binomial regression, which provides more accurate estimates of standard errors than the standard Poisson model. The approach is used to model count variables, such as the number of protests in a given year (Woolridge, 2009). Regression analysis allows us to account for multiple independent variable impacts on the dependent variable, where each variable has a partial effect in determining the dependent variable. The theory of Protracted Social Conflict calls for a dynamic model, where protesting and riots in the previous period may affect activity in the next period, so a lag of the dependent variable is incorporated to capture this dynamism. The analysis employs two different models, one looking at protests, and the other looking at riots. The use of a lagged variable also allows us to satisfy a key requirement for causation, which is temporal ordering of the cause and effect. The generalized equation for the model is:

$$
\text { NEvents } s_{t}=e^{x}
$$

where ${ }^{1}$ :

$$
\begin{gathered}
x=\beta_{0}+\beta_{1} \text { NEvents }_{t-1}+\beta_{2} \text { Count }_{t}+\beta_{3} \Delta G D P_{t-1}+\beta_{4} \text { PPopulationGrowth }_{t-1}+\beta_{5} \text { Polity }_{t-1} \\
+\beta_{6} \text { TradeRatio }_{t-1}+\beta_{7} \text { Diplomaticlntegration }_{t-1}+e_{t}
\end{gathered}
$$

\subsubsection{Data}

The dependent variable for this analysis is the number of events (protests or riots) that occurred in the area of study in a given year. While a measure of both the intensity of the event and the frequency of events would be preferable, the dataset does not have a robust way of accounting for intensity.

Accordingly, we focus only on frequency of events. The Global Dataset on Event, Location and Tone (GDELT) (Leetaru \& Schrodt, 2013) provides data drawn from machine-coding of written news articles from 1979 to present for event data. This analysis only runs through 2008 due to data limitations on other variables. It provides daily updates to the dataset. This dataset was collapsed into yearly counts of the event and then merged with other macroeconomic data for Pakistan. In Pakistan, there have been 68,070 events since 1979 (See Figure 2 - Map of Protest Events in Pakistan). There were 8,609 events geolocated in Karachi during this same time period (See Figure 3 - Map of Protest Events in Karachi). There is both strong temporal dependence in this variable and correlation with time. The correlation with time is driven by the increased availability of news reports over time. Accordingly, the model will include a count variable increasing by one for each year of data to control for this variation. Temporal dependence is controlled for with a variable counting the number of events in the previous time period.

\footnotetext{
${ }^{1}$ Data definitions for this model are included in Appendix 1. NEvents is a count of the number of events (either protests or riots).
} 


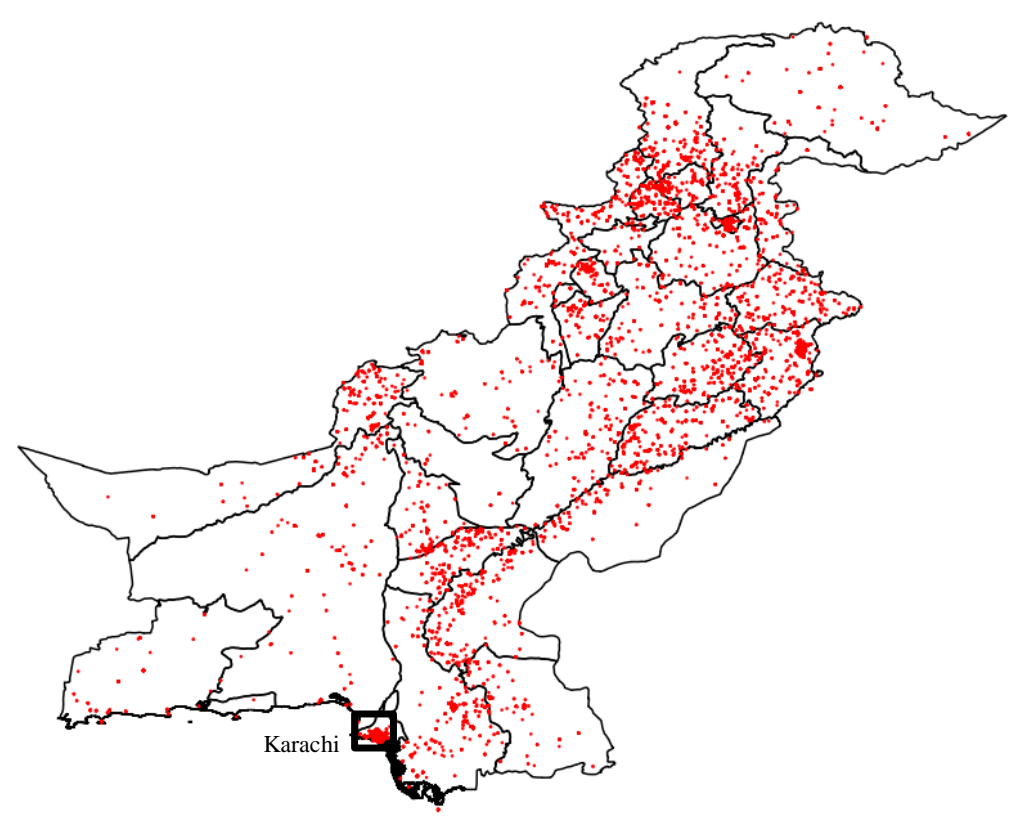

Figure 3 - Map of Protest Events in Pakistan

GDELT Conflicts, 1979-2013, Karachi, Pakistan

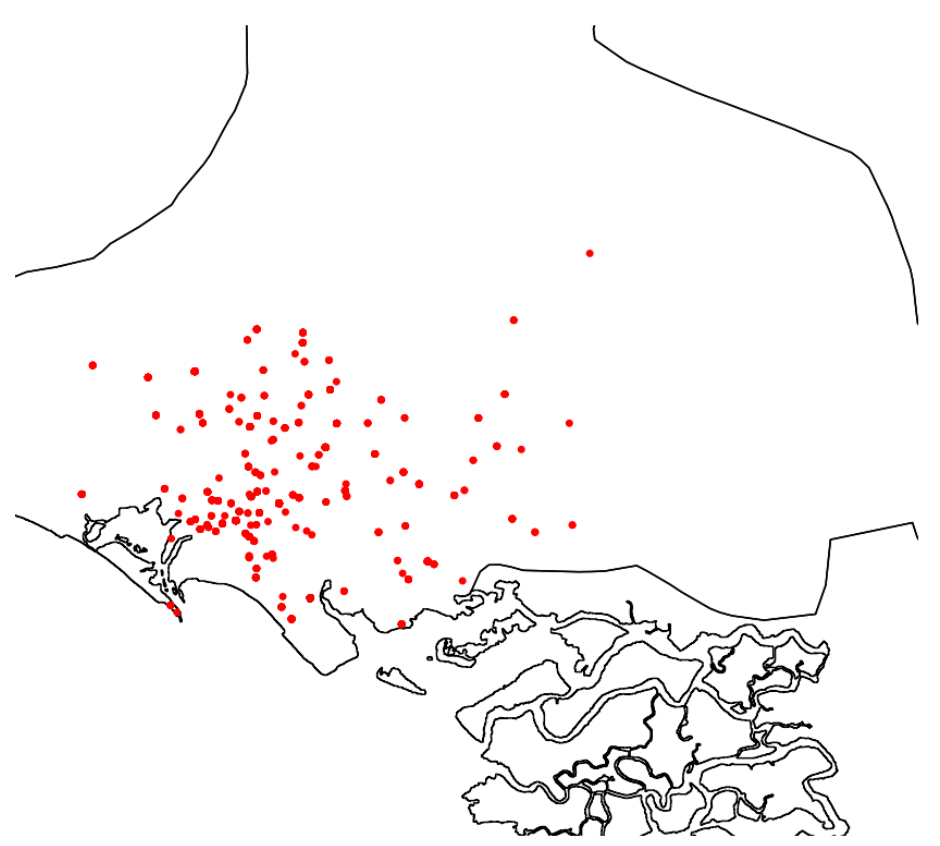

Figure 4 - Map of Protest Events in Karachi

\subsection{Results}


The models for both protests and riots are statistically significant. ${ }^{1}$ Independent variables have a similar effect in both the protest and riot models for each spatial scale. The Karachi model does surprisingly well when structural data from the state level is included with protest and riot data from the city level. Table 1 shows the results of the regression for both protests and riots. Insignificant variables are kept in the model because they are theoretically relevant and because omission may bias the results.

In the protest model, the number of events in the previous period is statistically significant (at a 95\% level) for the state level model, but not the Karachi model. This non-significant finding in the Karachi model could be a function of the data used for structural controls, which is not actually at the city level. In the riot model, the number of protest events is not statistically significant. This suggests that riots are potentially less predictable as a function of previous behavior. However, missing variables or small sample size could be affecting the insignificant finding.

Several factors are either not significant, or their sign changes, indicating that they have an inconsistent role as a predictor. These factors include GDP per capita change, trade ratio (although trade ratio significantly increases the risk of riot in the Karachi model) and diplomatic integration (although it significantly increases protests in the Karachi model).

Population change and polity (democracy vs. autocracy score) are both significant across specifications (although polity is insignificant in the Karachi riot model), suggesting that they are reliable estimators. Movement towards democracy reduces the likelihood of events. Population change has a large and significant effect on both types of events.

Significance may be under-stated in this model due to the small sample size. As sample size increases, standard errors get smaller and the significance score increases. Accordingly, it's important to understand the directions of effect in the estimates. Table 1 shows the direction of effect. Green is a positive effect (a change in $\mathrm{x}$ increases the dependent variable) and red is a negative effect (a change in $\mathrm{x}$ reduces the independent variable). Stars indicate significance levels.

Table 2 - Results of Regression

\begin{tabular}{|c|c|c|c|c|}
\hline & $\begin{array}{c}\text { Protest } \\
\text { Pakistan }\end{array}$ & $\begin{array}{l}\text { Protest } \\
\text { Karachi }\end{array}$ & $\begin{array}{c}\text { Riot } \\
\text { Pakistan }\end{array}$ & $\begin{array}{c}\text { Riot } \\
\text { Karachi }\end{array}$ \\
\hline N Events (Protest or Riot) & $* *$ & & & \\
\hline \multicolumn{5}{|l|}{ GDP/Capita Change } \\
\hline Population Change & $* * *$ & *** & $* * *$ & $* * *$ \\
\hline Polity & $* *$ & * & $* *$ & \\
\hline Trade Ratio & & & & $* *$ \\
\hline Diplomatic Exchange & & * & & \\
\hline $\begin{array}{l}* * * p<.01, * * p<.05, * p \\
\text { Red = Increases the numbe } \\
\text { Green = Decreases the nun } \\
\text { All independent variables } 1\end{array}$ & $\begin{array}{l}\text { f protests } \\
\text { ged protes one }\end{array}$ & $\begin{array}{l}\text { riots } \\
\text { or riots } \\
\text { me period }\end{array}$ & & \\
\hline
\end{tabular}

\footnotetext{
${ }^{1}$ Statistical significance is given by the log-likelihood and suggests that the model does better than a null model including only the count variable (controlling for increasing number of news reports over time) and an intercept at predicting the number of protests.
} 
In terms of model skill, it has relatively tightly clustered estimates and seems to match quite well with the shape of the actual events. Figures 4 and 5 show that most of the time, the predicted value is tightly clustered around the accuracy line (45 degree line in charts). Anything below the accuracy line shows that the prediction is too high and anything above it shows that the prediction is too low. The scatter in larger numbers is expected due to the scale of the observation. Karachi's predictions are less tightly clustered than Pakistan's, suggesting that data on structural factors may be less useful in that context due to the state-level of analysis for many variables. Regardless, the trend is generally favorable with regards to model fit.
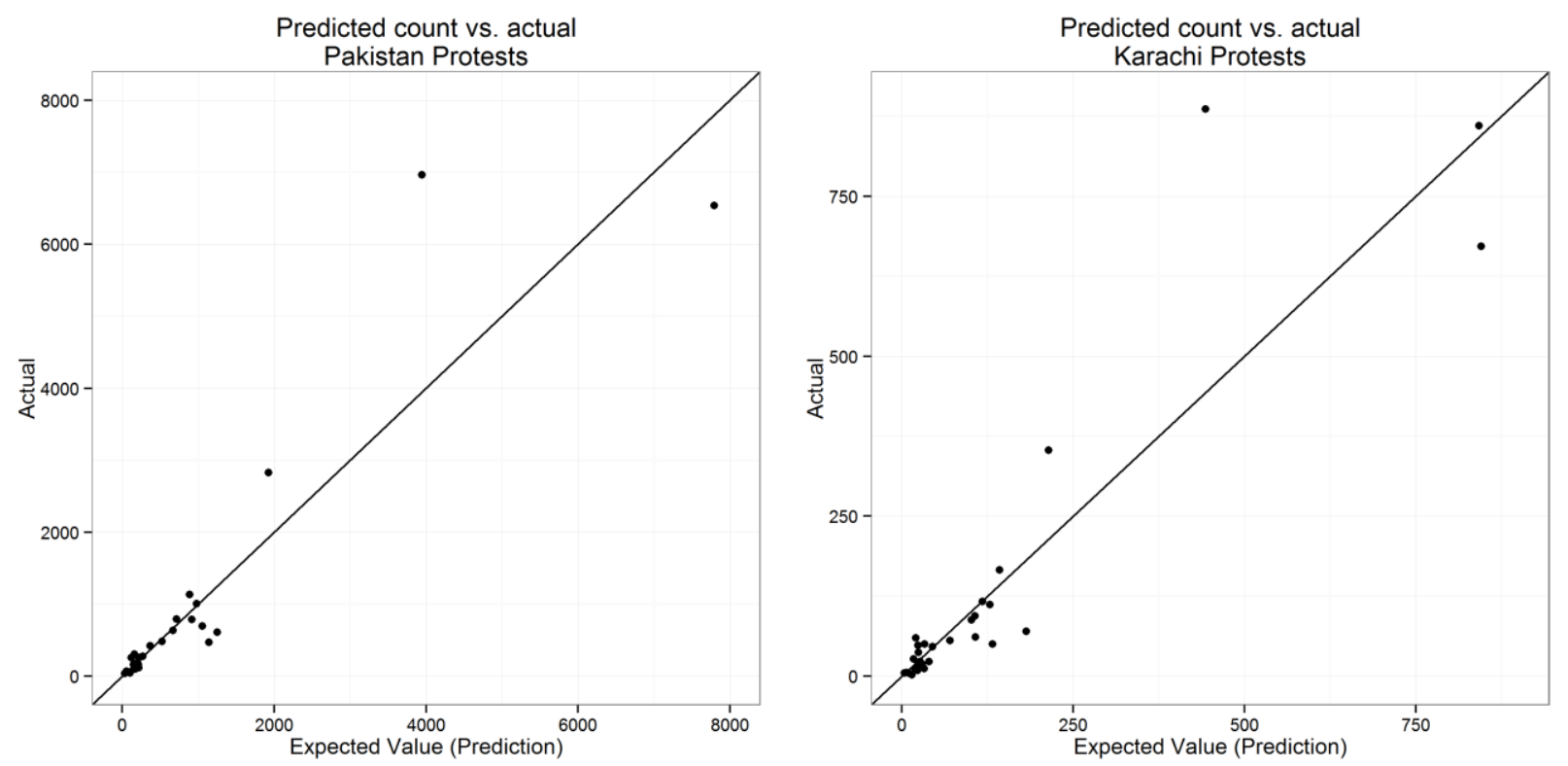

Figure 5 - Predicted Count vs. Actual - Protests
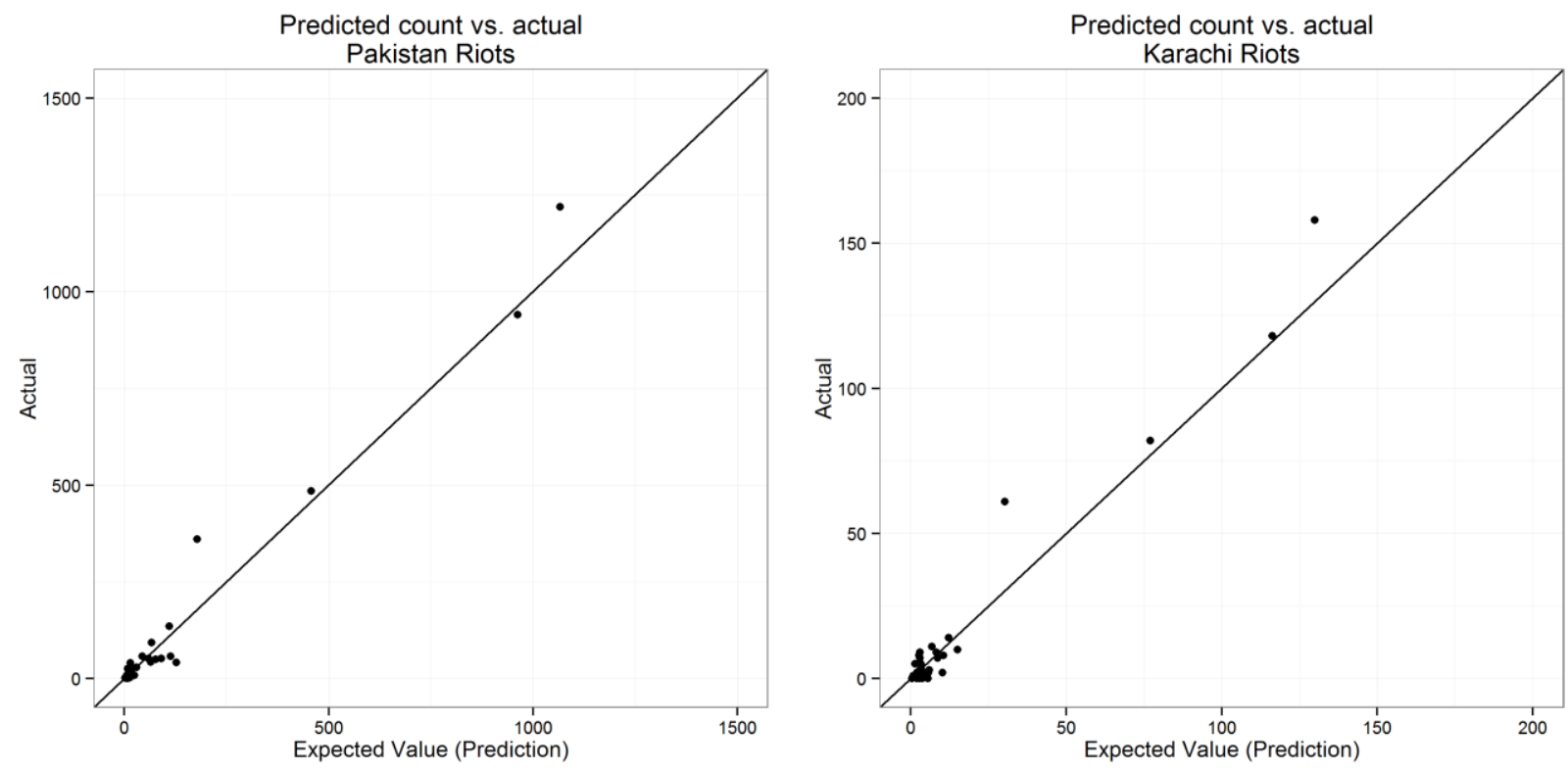

Figure 6 - Predicted Count Vs. Actual - Riots 


\subsection{Foresight Scan}

For the foresight scan, we build on the models from the hindsight scan, described in the previous section, to perform forward looking analysis using statistically realistic scenarios of future trends in Karachi. This section describes the approach and results at a high level. It highlights the scenarios that are employed, and then discusses the results and findings. The scenarios are fed into the models to provide a forecast of unrest (protests and riots) from 2008 to 2030 and iterated 1000 times. The end date is chosen arbitrarily. These forecasts are unlikely to "predict" an event, but can show the effect of various trends within the country, thus we call them foresights in practice. Five scenarios are considered (one as a baseline) in the analysis and then the relative difference in protests and riots are analyzed against the baseline. The average trend is considered, as well as both the best and worst case scenarios. These best and worst case scenarios are frequently called "black swans," and are low probability, high impact conditions that policymakers occasionally wish to understand (Taleb, 2007). The data informing these models is mostly at the state level, but the starting number of protests and riots is the lagged value at the city level. Table 2 summarizes the conditions for each scenario.

Table 3 - Scenarios

\begin{tabular}{|c|c|c|c|c|c|c|c|}
\hline Variable & $\begin{array}{c}\text { Average } \\
1979- \\
2008\end{array}$ & $\begin{array}{c}\text { Scenario } \\
\text { 1: } \\
\text { Baseline }\end{array}$ & $\begin{array}{l}\text { Scenario } \\
\text { 2: Pop } \\
\text { Growth }\end{array}$ & $\begin{array}{l}\text { Scenario } \\
\text { 3: Polity } \\
\text { Collapse }\end{array}$ & $\begin{array}{l}\text { Scenario } \\
\text { 4: Trade } \\
\text { Collapse }\end{array}$ & $\begin{array}{c}\text { Scenario } \\
\text { 5: Nat. } \\
\text { Disaster }\end{array}$ & $\begin{array}{l}\text { Scenario } \\
6: \text { Hybrid } \\
\text { of } 3 \& 5\end{array}$ \\
\hline Tested & NA & Yes & Yes & Yes & No & Yes & Yes \\
\hline GDP/Capita Change & 5.03 & 12.60 & S1 & S1 & S1 & $\begin{array}{c}\text { Affected } \\
\text { by } \\
\text { Disaster }\end{array}$ & $\begin{array}{c}\text { Affected } \\
\text { by } \\
\text { Disaster }\end{array}$ \\
\hline Population Change & 2.69 & 1.83 & $\begin{array}{c}2 \text { SD } \\
\text { Below } 10 \\
\text { Yr Mean }\end{array}$ & S1 & S1 & $\begin{array}{c}\text { Affected } \\
\text { by } \\
\text { Disaster }\end{array}$ & $\begin{array}{c}\text { Affected } \\
\text { by } \\
\text { Disaster }\end{array}$ \\
\hline Polity Change & 0.53 & 0.20 & S1 & $\begin{array}{c}\text { Random } \\
5 \text { Point } \\
\text { Decline }\end{array}$ & $\mathrm{S} 1$ & S1 & $\begin{array}{c}\text { Random } \\
5 \text { Point } \\
\text { Change }\end{array}$ \\
\hline Trade Ratio Change & 0.53 & 2.93 & S1 & S1 & $\begin{array}{c}2 \text { SD } \\
\text { Below } 10 \\
\text { Yr Mean }\end{array}$ & S1 & S1 \\
\hline $\begin{array}{l}\text { Diplomatic Exchange } \\
\text { Change }\end{array}$ & -1.10 & 0.51 & S1 & S1 & S1 & S1 & S1 \\
\hline
\end{tabular}

NOTE: S1 means that the data matches with scenario 1, S2 means that it matches with scenario 2, etc.

Scenario one is a baseline scenario using statistical trends from Pakistan's recent past. It uses average values of change in data from the last 5 years. There is no stochastic element to the analysis, aside from the built-in standard errors of the model.

Scenario two is a scenario examining rapid population growth in Pakistan, which translates more severely into action in Karachi than Pakistan ${ }^{1}$, possibly because population growth is centered in urban areas.

\footnotetext{
${ }^{1}$ From the hindsight scan a $1 \%$ change in population growth in Pakistan yields 4.8 times more protests in Pakistan, but 12.28 times more protests in Karachi. Similarly, a 1\% change in population growth in Pakistan yields 11.47 times more riots in Pakistan, but 19.2 times more protests in Karachi.
} 
Karachi's growth rate between 1981 and 1998 (the last available census data) was $3.49 \%$ per year, compared to a $3.01 \%$ rate in all of Pakistan. ${ }^{1}$ All components of scenario 1 remain stable in scenario 2 except for population change, which is increased to two standard deviations of the average $(2.69 \%$ growth).

Scenario three introduces a stochastic component where polity declines by 5 points in a single year randomly with an independent probability of $10 \%$. This simulation only allows for a single decline in the given time period, although it is possible to eliminate this constraint. This scenario is run 1000 times to identify an average value of change.

Scenario four incorporates randomly timed shifts in trade of two standard deviations below the ten year average. It is not operationalized in this model due to time constraints and because the scenario was deemed a low priority by the research team.

Scenario five addresses the question of impacts from natural disasters. It is assumed that a "major" disaster (discussed later in this paragraph) occurs with a probability of $2 \%$ in a given year and that all types of disasters are equivalent in impact, aside from the intensity of that impact. There is no limit on the number of consecutive events (one per year) that can occur. For the purposes of this analysis, estimates from a World Bank Report (Hochrainer, 2009) are used to assess impacts on economic growth. To assess impacts on population, a UN dataset on average annual deaths from natural disasters is employed. To assess average deaths and to add a stochastic element, each disaster is assigned an intensity value randomly (from -1 to 1) and then that intensity is used to vary the death toll between a plus one standard deviation toll and a minus one standard deviation toll. The models representing impacts from natural disaster are admittedly weak, but provide a starting point for analysis. Future research should focus on improving these impact assessments to build a more robust measure of impact on all of the relevant parameters in the model.

Scenario six draws on both the polity component of scenario 3 and the natural disaster component of scenario five.

\subsection{Results}

This foresight scan identifies one key change as posing a major threat to Karachi. Population change of two standard deviations higher than the average change increases the number of protests significantly from a baseline scenario as shown in Figure 6 . The dotted lines represent $95 \%$ confidence intervals, suggesting that $95 \%$ of the time, the expected value of protests will fall between those lines. The fact that these lines do not overlap in the forecast period suggests a very large, very significant difference in likelihood of protests in Karachi given large population growth in Pakistan (and an assumed higher rate of population growth in Karachi). The pattern holds for riots. Two standard deviation changes are not uncommon in Pakistan's past, and in a large urbanizing city like Karachi, it is likely that there will be periods of high population growth.

\footnotetext{
${ }^{1}$ Drawing from http://www.pbs.gov.pk/sites/default/files/tables/POPULATION\%20SIZE\%20AND\%20GROWTH\%20OF\%20MAJ OR\%20CITIES.pdf and state level data from World Bank.
} 

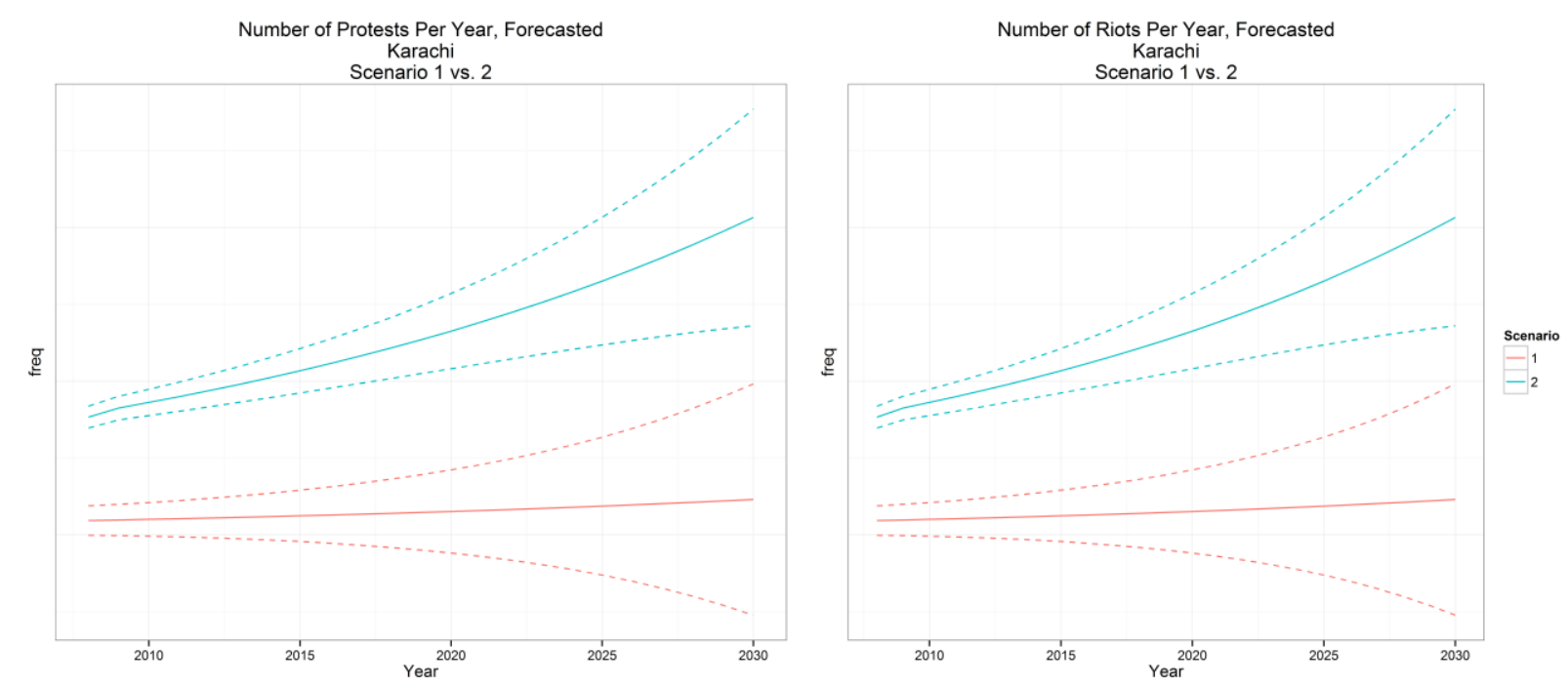

Figure 7 - Scenario 1 vs. 2 Comparison

In comparison, the other scenarios are not significantly different from the baseline scenario. Figure 7 shows the expected values of protest given each scenario. Given that several of the scenarios overlap so closely that they are not even visible, there is not a strong difference between them.
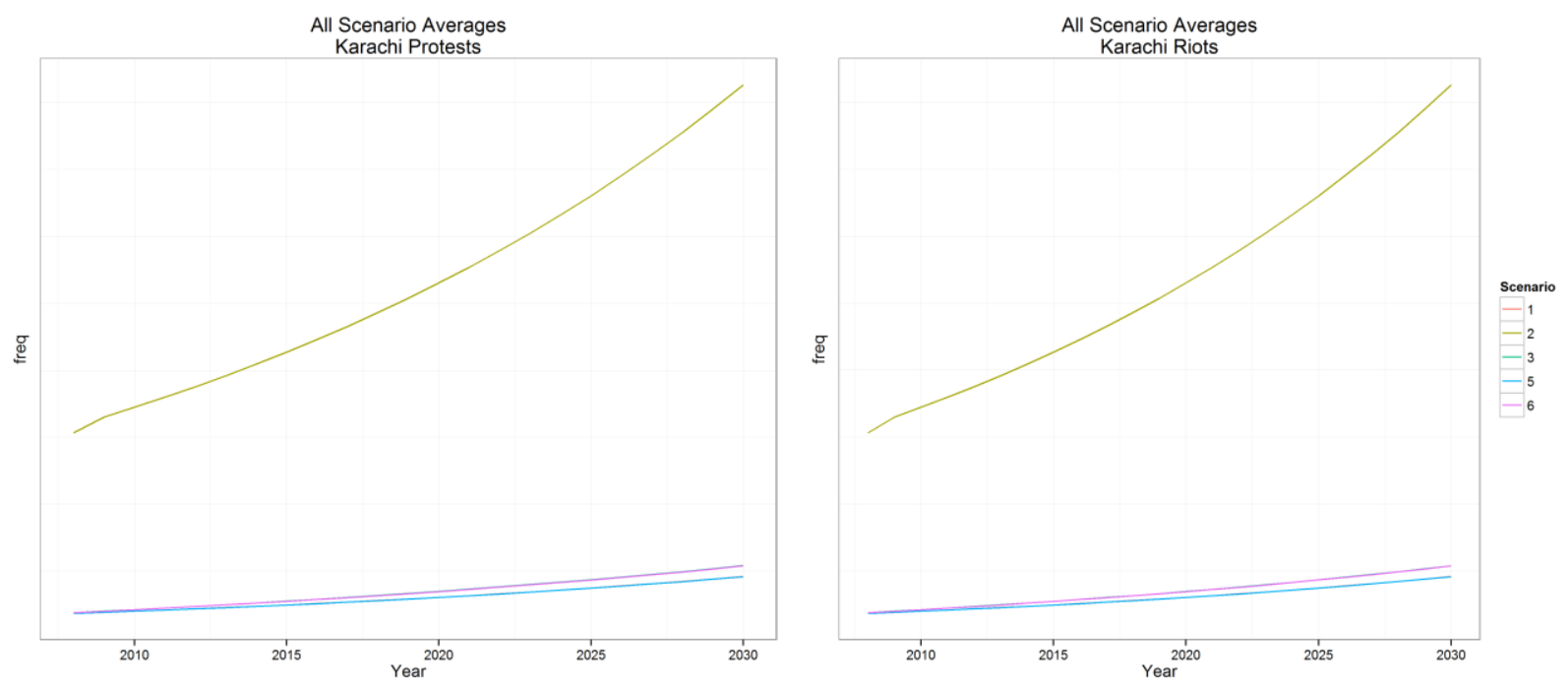

Figure 8 - Compare all Scenarios

The analysis suggests that natural disasters (as modeled in this simulation - scenario 5) are unlikely to have a major effect on stability in isolation (See Figure 8). Scenario 6 shows that natural disaster and political change combined have an effect, but it is mostly driven by the political collapse scenario. However, the models employed for natural hazards are weakly defined and based on extremely simplistic models. A better understanding of the effects of a natural disaster on population change dynamics like migration to and from an area would benefit this analysis considerably. A more complete estimator of economic impacts would also likely improve the validity of this scenario. Finally, there is the possibility that risk to disaster will not remain steady over time as modeled in this analysis. There is a distinct possibility that risk will increase over time as climate change and other disasters increase vulnerability to 
disasters. Further, major natural disasters outside of the directly modeled area may lead to increased population growth in Karachi and increase the risk of unrest.
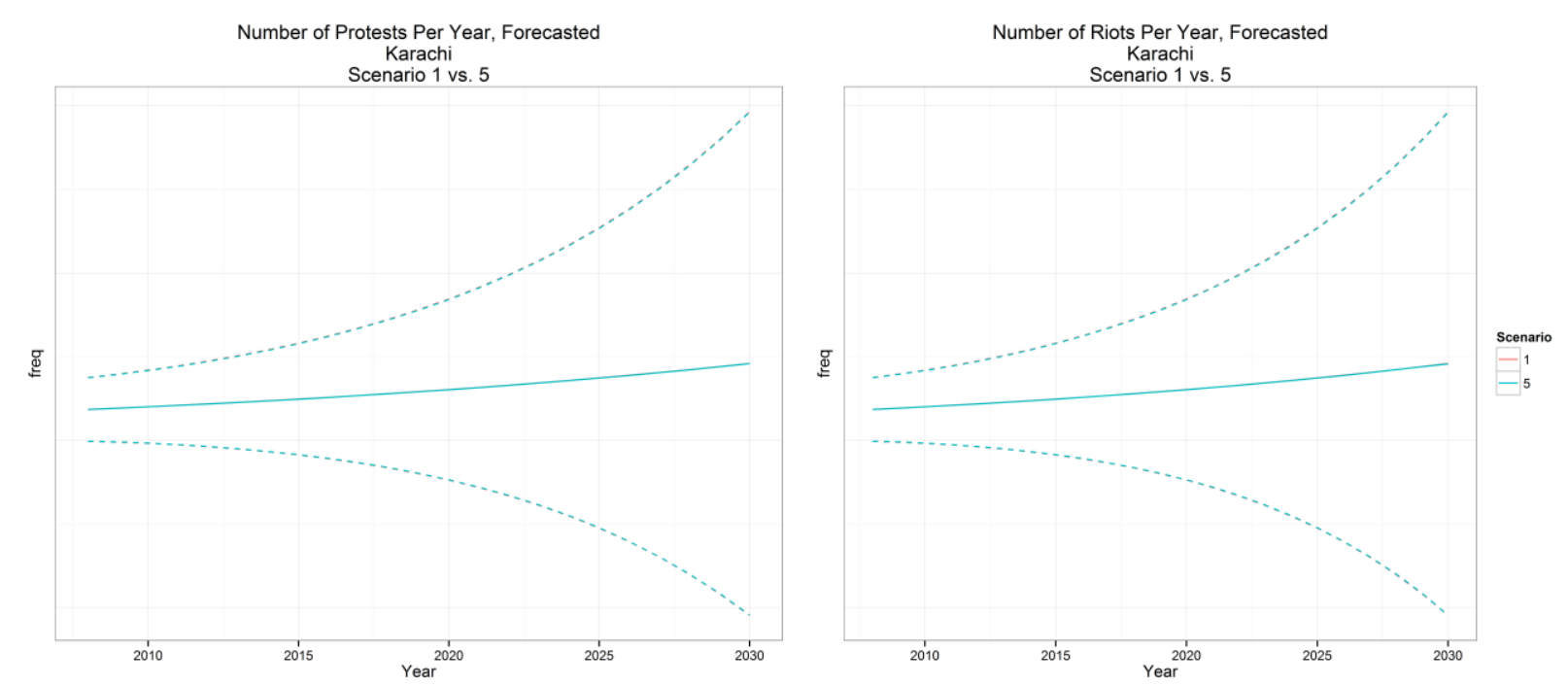

Figure 9 - Scenario 1 vs. 5 Comparison

Another constraint on these models is the wide range of uncertainty in each. Even in scenario 2, the uncertainty of the estimates is very large. This uncertainty likely comes from two factors: 1) an incomplete model of protest and riot and 2) data problems. All models are necessarily a simplification of the world, so uncertainty is natural. However, the model employed in this analysis is very simple and derived from a very small dataset. The initial model dataset size means that forecast standard errors are quite large (standard error usually decreases as sample size increases, if the measure is valid). It is also limited by the number of factors that can be included in the model because of that sample size. To increase sample size, a model looking at multiple cities over long timelines in the form of panel data analysis would yield benefits. These models also have data problems that are likely driving additional uncertainty by assuming that Karachi's experience with demographic change, economic well-being and other factors is well-represented by national level data. We know that Karachi's growth rate was larger than Pakistan's averages from 1981-1999, so there is no reason to believe that it is similar today. This problem can be resolved by acquiring city level, or even province level data.

In considering an scenarios 3-6, it can be useful to think about the best case, worst case and average case. This helps to characterize black swan events. Many policymakers work in an environment where black swan events can generate significant surprise and have negative impacts. The black swan analysis for scenario 6 yields the most interesting charts (Figure 10). In the protests best case scenario (i.e. lowest number of events in one period), there are two disasters, suggesting that back to back disasters make social unrest less likely and then there is a democratic reversal in 2021 returning it to the same number of protests as the worst case. The worst case scenario (i.e. the highest number of events in one period) has no disasters and just a democratic reversal. For the black swan analysis of riots in scenario 6, a similar pattern is observed, just earlier in the timeline. Protests decrease at the time of the disaster and then a democratic reversal a couple of years later increases the number of protests. In the worst case scenario, it is once again just a democratic reversal with no natural disaster. 

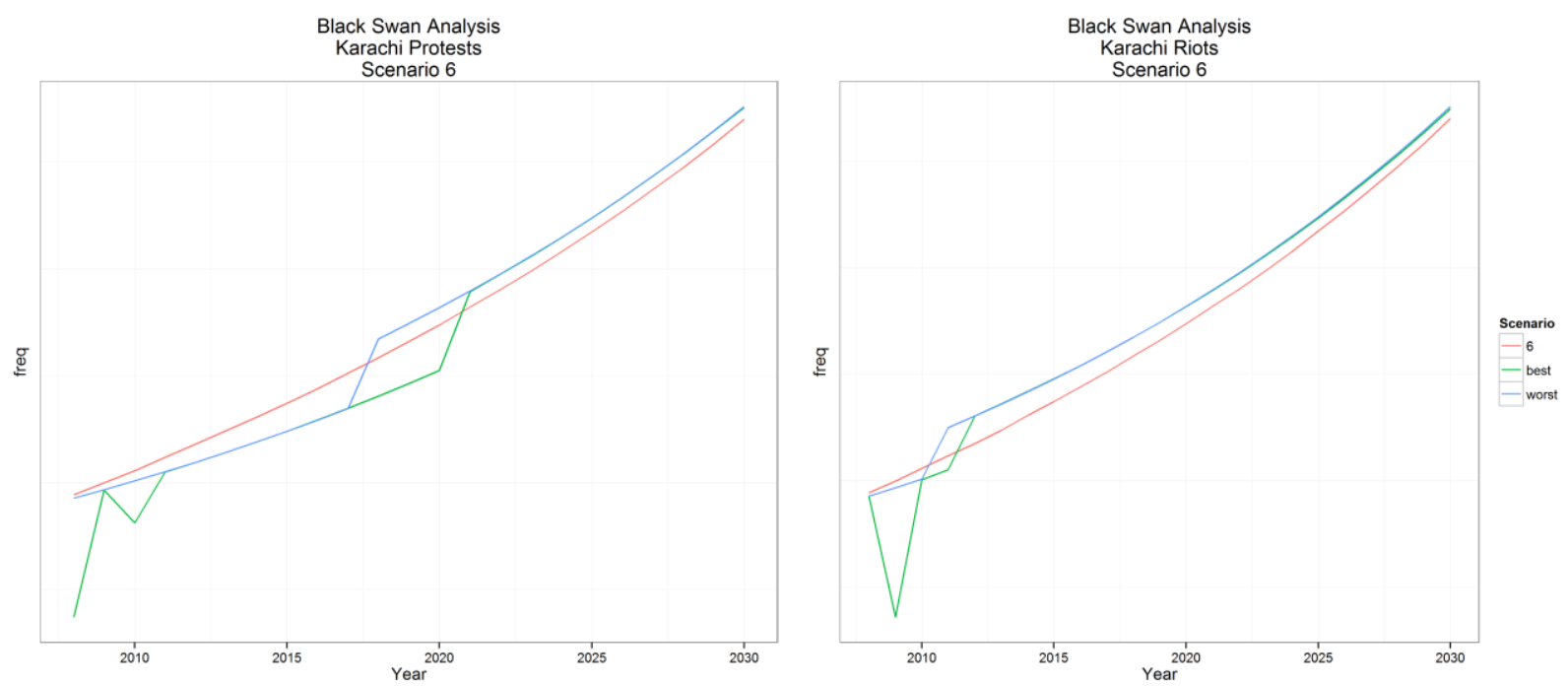

Figure 10 - Scenario 6 Black Swans

\subsection{Findings and Recommendations}

Both the hindsight and the foresight scan show that demographic change is very important to understanding protests and riots in Karachi. The effect is large and significant. This suggests that trends suggesting increased urbanization may drive up the risk in Karachi. This specific analysis finds no relationship between natural hazard and unrest, but this may be a modeling issue related to the weakly formed models in the natural hazards analysis. This section discusses the strengths of the analysis and highlights some weaknesses that can be addressed to improve the modeling.

This research was motivated by a need to understand social unrest, which could diminish U.S. National Security and to better understand the comments made about unusable models of conflict made during the elastic futures workshop. Policymakers noted that models are insufficient for day to day decision-making, but provided little other context (Kurzrok, 2013). We show that existing state level models of unrest could be improved in spatial scale to the city level, even without significantly improved data access. Better data would make this analysis more complete and likely improve the quality of the model. Another challenge with incorporating modeling into decision-making is the need to understand uncertainty in a model. Policy makers are frequently tasked with making decisions without a clear outcome, so characterization of uncertainty is critical (Unwin, Moss, Rice, \& Scott, 2011). This analysis provides a view into both the confidence of the analysis (confidence intervals in the predictions) and black swan events, where a low probability, high impact event occurs. While black swan events are by their nature unpredictable, they are also important to understand for policymakers to help prepare a robust plan.

There are also weaknesses to this analysis. In order to understand the concerns by policymakers, it was necessary to push the models to understand the shortcomings of the models and develop a forward looking research agenda. The main weaknesses include data availability, model uncertainty and the quality of scenarios.

The findings from this research suggest that modeling at the city level is feasible, but incomplete with existing data capabilities. It is critical to understand the limitations of models in policymaking applications to avoid over reliance. George E.P. Box (1987) reminds us that, "all models are wrong; the practical question is how wrong do they have to be to not be useful." Fundamentally, that is the question under analysis here. Data limitations and sample size limit the reliability of the findings. While the model 
is accurate in terms of the data it was fitted against, this is to be expected as the regression uses that data to make a best guess in terms of variable effects. Validity for extrapolating this model may be reduced by the limited sample size. Additionally, alternative variables can be employed to assess the best proxies for the concepts posed by the PSC. Alternative validation approaches should be considered to enhance qualitative confidence in the models. The spatial scale of the data is also limiting. Structural variable data came only from the state level, but city level data would be better. Data is available for purchase from the Government of Pakistan's statistics office. While imperfect, it would likely be more relevant to the city level than the state level data. This would also allow for comparative analysis between major metropolitan areas using panel data, which would increase the sample size considerably and also yield more reliably generalizable findings.

Model uncertainty is also driven partially by data constraints. Even in scenario 2, which exhibits strong statistically valid findings, the uncertainty of the estimates is very large. This uncertainty likely comes from two factors: 1) an incomplete model of protest and riot and 2) data problems. All models are necessarily a simplification of the world, so uncertainty is natural. However, the model employed in this analysis is very simple and derived from a very small dataset. The initial model dataset size means that standard errors are quite large (standard error usually decreases as sample size increases, if the measure is valid) and the estimated uncertainty in the model is also necessarily large. It is also limited by the number of factors that can be included because of that sample size. To increase sample size, a model looking at multiple cities over long timelines in the form of panel data analysis would yield benefits. Additionally the use of state level data to model city-level phenomena may be contributing to additional uncertainty. Much of this challenge would be resolved with higher resolution data.

Finally, the quality of scenarios and the sub-models employed in the scenarios may also affect the analysis. This refers to box 1 and the arrow from box 1 to box 2 in Figure 1 . The natural hazard effect scenario stands out as the most problematic. The models employed are weakly defined and extremely simplistic, with very few controls. A better understanding of the effects of a natural disaster on population change dynamics like migration to and from an area would benefit this analysis considerably. A more complete estimator of economic impacts would also likely improve the validity of this scenario. Finally, there is the possibility that natural hazard risk will not remain steady over time as modeled in this analysis. Between climate change, a key risk factor for many natural disasters, and the effects of natural disasters, which may increase vulnerability to natural disaster, there is a distinct possibility that risk to natural hazards will increase over time. Further, major natural disasters outside of the directly modeled area may lead to increased population growth in Karachi and increase the risk of disaster. Some models of vulnerability to climate change, like the Vulnerability Resilience Indicator Model (Moss, Brenkert, \& Malone, 2001) might help to inform this scenario analysis.

Before major conclusions are drawn about this foresight scan, it is clear that more research should be done to improve the models and their external validity, which means focusing more research in boxes 2 and 3 of Figure 1. A research agenda focused on the suite of models needed to perform this analysis would help to reduce model uncertainty, which is considerable. Key focuses of this research agenda should include

1) acquisition of city level data (Box 2, Figure 1)

2) improved models of the effect of natural disaster, specifically demographic change due to migration and the impact on economic growth (Box 1, Figure 1)

3) improved models of the dynamics of economic growth (Box 1, Figure 2)

4) improved scenarios, possibly derived from climate assessment models that forecast both economic growth and many natural disasters (Box 1 Figure 1). 
To further bolster the analysis and its relationship to U.S. national security, work could be done to test the relationship between social and political instability and U.S. security (Boxes 4 and 6, Figure 1) and between riots and protests and social and political instability (Boxes 3 and 4, Figure 1). These are assumed as true for this analysis, but could strengthen the value of the models.

One way to build on this concept would be to model protest and riots in the United States. There have been several major natural disasters in areas of interest to the U.S., including New York (Hurricane Sandy) and New Orleans (Hurricane Katrina). Not only are the areas interesting because of their natural disaster impacts, but they are areas that have experienced considerable social strife. Finally, as U.S. cities, data is both more readily available and possibly more reliable than from countries like Pakistan. These models will not necessarily generalize to other countries, but the methodology could be advanced in a more familiar region and then employed to analyze regions with more difficult to acquire data.

Alternatively, if Pakistan remains the modeling topic, data can be acquired about city level indicators of demographic change, population change and other factors to inform the model. It would require a shorter modeling time horizon (Pakistan's statistical office has reliable numbers going back only to 2004), but then all of the cities in Pakistan could be included in the panel, yielding several years of data in at least a dozen cities, which would double (at a minimum) our sample size and also probably yield a substantial reduction in uncertainty.

\subsection{Conclusion}

This modeling exercise provided a rigorous and replicable analysis of social unrest in Karachi from both a historical and a forward-looking perspective. It employed historical data from Pakistan and Karachi to build a negative-binomial regression model. This model was employed with five scenarios looking at statistically plausible scenarios for Karachi's near future in order to understand potential future threats. The results of both the hindsight and the foresight scan suggest that periods of large population growth in Karachi represent a high potential for social unrest.

This effort also helped to address concerns that models of social stability are not useful to policymakers by providing more temporally and geographically disaggregated forecasts. This is accomplished by downscaling a state level theoretical concept (PSC) to the city level and modeling it at the city level. It characterizes uncertainty and clearly addresses its assumptions so that policymakers can better understand the constraints of the data. In doing so, it highlighted a potential research agenda that will aim to improve the scenarios under analysis, gain better access to data and more carefully model some of the sub-models required for scenario analysis.

The study addresses a small portion of the Global Risk Initiative Analytical Framework, which can be used to help guide and understand future research. Additional research is necessary to explicitly tie social unrest in the form of protests and riots to social and political instability, and even more research is necessary to understand the empirical relationship between instability in other countries and cities to U.S. national security. A research agenda that aims to improve the models we developed to understand riots and protests and then more explicitly links those impacts to national security would likely provide information for policymakers that could aid in decision-making. 


\subsection{Appendix 2 - Hindsight Scan Methodology}

Based on the findings from the literature review, the quantitative component of this paper operationalizes Azar's model of Protracted Social Conflict at the Pakistan and Karachi levels, respectively. Accordingly, three hypotheses are considered.

Hypothesis 1: A model of Pakistan's social unrest is statistically valid at the state level Hypothesis 2: Data exists to downscale the state model to evaluate social unrest in Karachi Hypothesis 3: A model of Karachi's social unrest is statistically valid

The model will employ a time-series analysis using a special type of Poisson regression called the Negative Binomial regression. Poisson regression is used to model count variables, such as the number of protests in a given year. However, data that are over-dispersed towards zero will yield an over-estimate of the statistical effect and significance of individual variables (Woolridge, 2009). The theory of Protracted Social Conflict calls for a dynamic model, where protesting and riots in the previous period may affect activity in the next period. Therefore a lag of the dependent variable is incorporated in the model to capture this relationship. The generalized equations for the two models are:

$$
\begin{gathered}
\text { NProtests }_{t}=e^{x} \\
\text { NRiots }_{t}=e^{x}
\end{gathered}
$$

where:

$$
\begin{gathered}
x=\beta_{0}+\beta_{1} \text { NProtests }_{t-1}+\beta_{2} \text { Count }_{t}+\beta_{3} \Delta \text { GDP }_{t-1}+\beta_{4} \text { SPopulation }_{t-1}+\beta_{5} \text { Polity }_{t-1} \\
+\beta_{6} \text { TradeRatio }_{t-1}+\beta_{7} \text { DiplomaticIntegration }_{t-1}+e_{t}
\end{gathered}
$$

\subsection{Data}

There are two dependent variables in this analysis, the number of protests and the number of riots that occurred in the area of study in a given year. The Global Dataset on Event, Location and Tone (Leetaru \& Schrodt, 2013) provides data drawn from machine-coding of event data from written news articles from 1979 to 2013. It provides daily updates to the dataset. This dataset was collapsed into yearly counts of the event and then merged with other macroeconomic data for Pakistan. In Pakistan, there were 68,070 events between 1979 and 2013 (See Figure 11 - Map of Protest Events in Pakistan). The dataset occasionally is not able to provide a precise location for each event, but it is assumed that these errors are randomly distributed and do not bias the estimator. There were 8,609 events geo-located in Karachi during this same time period (See Figure 12 - Map of Protest Events in Karachi). There is both strong temporal dependence in this variable and correlation with time. The correlation with time is driven by the increased availability of news reports over time. Accordingly, the model includes a count variable increasing by one for each year of data to control for this variation. Temporal dependence is controlled for with a variable counting the number of events in the previous time period.

\begin{tabular}{lccccc} 
& \multicolumn{5}{c}{ Table 4 - Descriptive Statistics } \\
Factor & Mean & Min & Max & N & SD \\
Year & 1996 & 1979 & 2008 & 30 & 8.8 \\
Protests & 868.3 & 39 & 6965 & 30 & 1688.125 \\
Riots & 49.65 & 0 & 940 & 30 & 192.3109
\end{tabular}




\begin{tabular}{|c|c|c|c|c|c|}
\hline Protests Lag $1 \mathrm{Yr}$ & 650.3 & 0 & 6965 & 30 & 1310.478 \\
\hline GDP Change Lag & 5.154 & -9.757 & 16.263 & 30 & 7.57961 \\
\hline Population Change Lag & 2.758 & 1.792 & 3.476 & 30 & 0.59762 \\
\hline Polity Lag & -0.5333 & -7 & 8 & 30 & 6.678495 \\
\hline $\begin{array}{l}\text { Trade Ratio Lag } \\
\text { Diplomatic Integration }\end{array}$ & 33.16 & 27.35 & 44.1 & 30 & 4.095032 \\
\hline Lag & 49.65 & 22.71 & 80.14 & 30 & 16.32741 \\
\hline
\end{tabular}

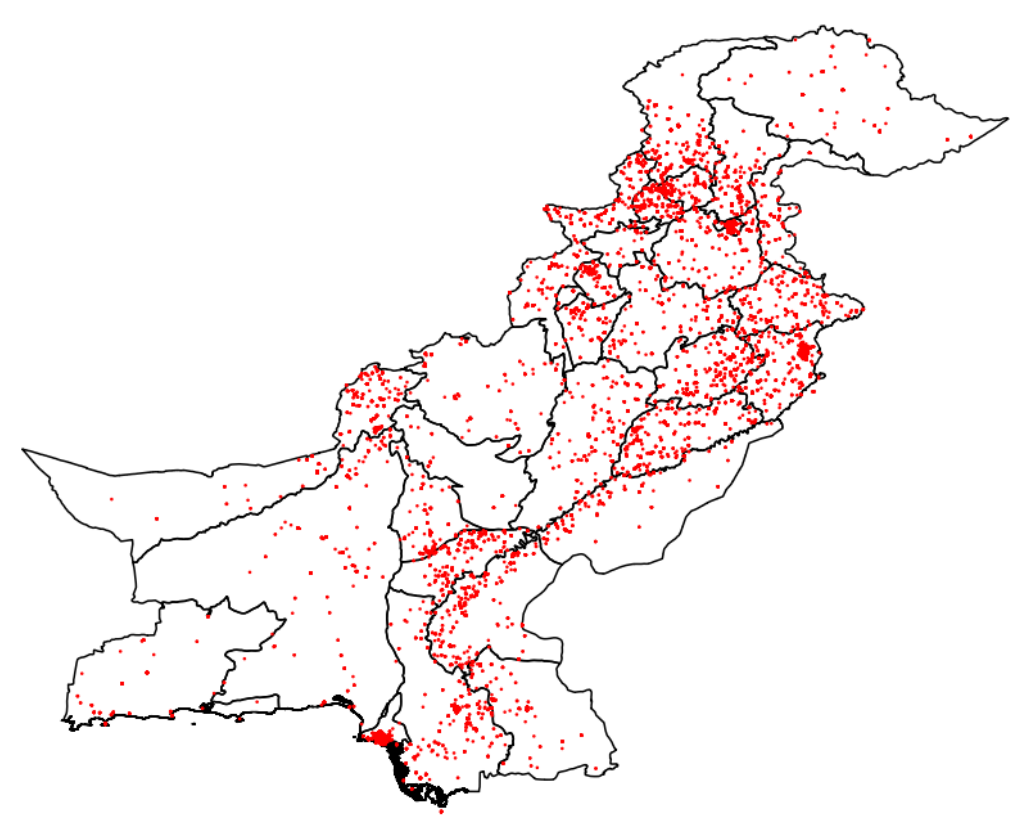

Figure 11 - Map of Protest Events in Pakistan 
GDELT Conflicts, 1979-2013, Karachi, Pakistan

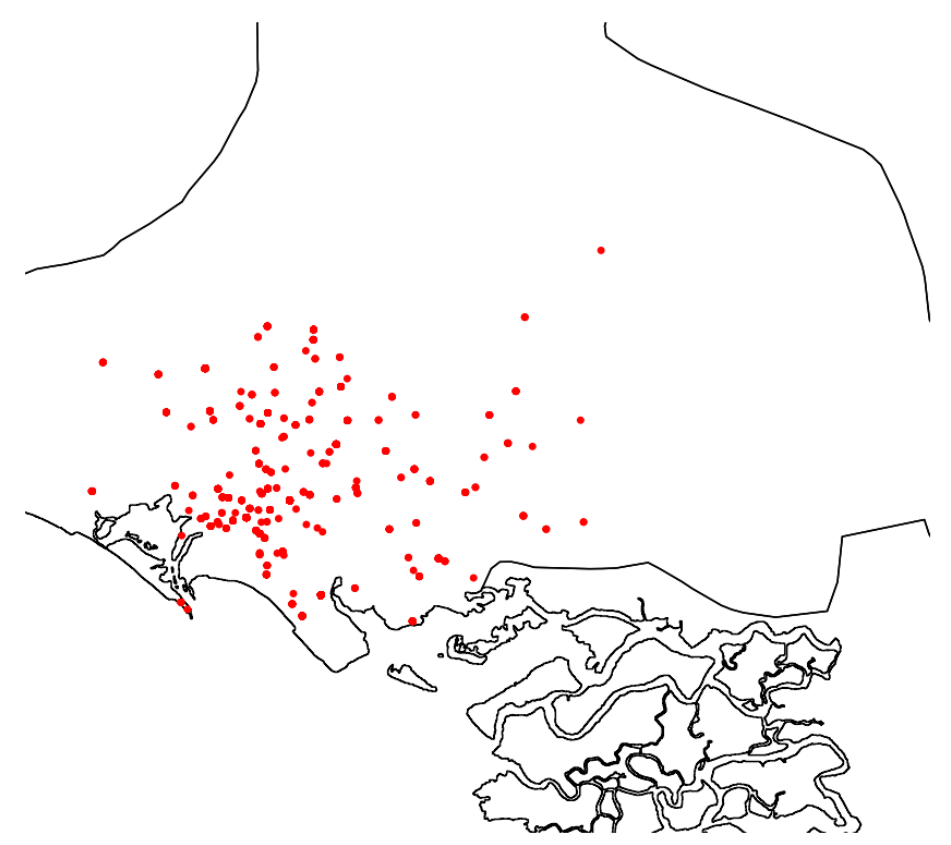

Figure 12 - Map of Protest Events in Karachi

GDP and Population data are drawn from the World Bank's Global Development Indicators (World Bank, 2013). GDP per capita is calculated as GDP/Population. GDP per capita change is the percentage change from the previous period to the current period. This first-differenced figure is both interesting from a modeling perspective and necessary from a statistical perspective to "de-trend" the variable ${ }^{1}$ and to avoid multicollinearity between it and other trend stationary variables. Population change is also first differenced to avoid trend stationarity problems.

Polity is drawn from the Polity IV index, version 2012 (Marshall \& Gurr, 2010). It is an index measure of the type of government ranging from -10 (full autocratic structure) to 10 (full democratic structure). Due to multicollinearity, the complementary measure "anocracy" is dropped from the model. Anocracy is a measure of the consolidation of a governing structure towards either full democracy or full anocracy and away from anarchy. Within a single state model such as this one, changes in democracy or autocracy are likely to take place in the more anocractic (anarchy-like) range of the scale, which causes the multicollinearity issues.

Trade import and export data are taken from the Correlates of War dataset (Barbieri, Keshk, \& Pollins, 2009) and normalized to 2012 dollars, consistent with the data from the World Bank's Global Development Indicators. It is calculated as the volume of trade (imports + exports) divided by total GDP. Diplomatic Exchange is drawn from the Correlates of War dataset (Bayer, 2006). It counts the percentage of total diplomatic exchanges Pakistan is involved in, out of the total number possible. This is a network figure and gives equal weight to all relationships. It assumes that all diplomatic relationships are equal. Alternative formulations may be valuable, where certain diplomatic exchanges are more important than

\footnotetext{
${ }^{1}$ De-trending is a statistical method to remove trend stationarity problems that could over-estimate the significance of a model. If the dependent variable and one or more independent variables have similar trends over time due to unrelated processes (e.g. both increasing) then there is a risk of over-stating the importance of those variables. First differences are the best approach for handling this problem, which then looks at the change in a variable from $t-1$ to $t$ (Woolridge, 2009, pp. 366-367).
} 
others due to normative country-level issues. For example, a relationship with Sweden may yield different conflict behavior than a relationship with Russia.

Due to the small sample size and data availability, some potentially relevant variables are excluded from the model. Future research could work to characterize the importance of factors like ethnic content and inequality on the predictions in this model.

\subsection{Results}

The models for both protests and riots are statistically significant. Independent variables have a similar effect in both the protest and riot models for both the state level and the city level models. There is strong support for hypotheses 1 and 3, and marginal support for hypothesis 2. Some data do exist to downscale PSC to the city, but city-level structural data iare not as easily available as state level data. However, the Karachi model does surprisingly well when structural data from the state level is included with protest and riot data from the city level. Table 1 shows the results of the regression for both protests and riots.

In the protest model, the number of events in the previous period is statistically significant (at a 95\% level) for the state level model, but not the Karachi model. The non-significant finding in the Karachi model could be a function of the data used for structural controls, which is not actually at the city level. In the riot model, the number of protest events is not statistically significant. This suggests that riots are potentially less predictable as a function of previous behavior. However, missing variables or small sample size could be affecting this result.

Time is significant in all four models, suggesting at a minimum that differences in the measurement of the dependent variable are important to control for. For each one year increase from 1979, the number of protests increases by $26 \%$ in the protest model and roughly $33 \%$ in the riot model. This difference is likely driven by two factors - omitted variables and an increased likelihood to document riots as time increases. Omitted variables may include things like technology and information availability. However, most of the effect is probably driven by the number of electronic articles available for the machine to code in the GDELT dataset.

GDP per capita change is not significant in any specification. Its sign also flips between the state level and city level model protest models, suggesting that it is not particularly useful as an indicator of protest risk. Its sign is insignificantly positive in the riot model. Alternative measures of income or individual need may be useful, but would require additional data acquisition.

Alternatively, population change has a very strong and highly significant effect in both models. In the state level model, a one percent increase in the population yields 4.8 times as many protests. In the Karachi model, a similar increase yields 11.5 times as many protests. The effect on riots is even larger, yielding 12.28 and 19.16 times as many riots in Pakistan and Karachi respectively. This large value seems extreme, until one realizes that in 2012, the population of Pakistan was about 179 million. A one percent increase is growth of over 1,000,000 people. In 2012, population growth was approximately $1.8 \%$ in Pakistan.

Polity has a significant negative effect on protests in both models and riots for the state-level model, where a one unit change in Polity (towards democracy on the 20 point scale) decreases the number of protests by .96 percent. This is a small effect, but it is significant at the $95 \%$ and $90 \%$ level for Pakistan and Karachi, respectively. The effect on riots is roughly the same, but insignificant at the Karachi level. This insignificance suggests that perhaps Karachi is not experiencing state level changes the same way 
Pakistan is. This could be a side-effect of over-crowding and poor governance in megacities. More research would be necessary to unpack this situation.

Trade ratio has no significant effect in either protest model. In the riot model, trade ratio has no effect at the state level, but significantly increases the risk of riots in the Karachi model. A one percent increase in trade ratio increases the number of riots by about 13 percent with better than $95 \%$ confidence. This result suggests that the effect of international integration could be double-edged, where it may increase or decrease the number of protests, but not in a systematic way.

Diplomatic integration has a small effect in the city model for protests only, suggesting that diplomatic integration increases the protest count by about 1 percent for every 1 percent increase in diplomatic integration. This is significant at a $90 \%$ level. A similar effect size is observed in the non-significant Pakistan model and both riot models.

Table 5 - Regression Results, Protests and Riots ${ }^{1}$

\begin{tabular}{lcccc}
\hline & Protest-Pak & Protest-Kar & Riot-Pak & Riot-Kar \\
\hline Intercept & 0.0300 & $0.0001^{* *}$ & $0.0001^{* *}$ & $0.0000^{* * *}$ \\
& $(2.4218)$ & $(3.5045)$ & $(4.3402)$ & $(5.7651)$ \\
N Events & $1.0002^{* *}$ & 1.0010 & 1.0002 & 1.0005 \\
& $(0.0001)$ & $(0.0008)$ & $(0.0001)$ & $(0.0012)$ \\
Time Count & $1.2616^{* * *}$ & $1.3499^{* * *}$ & $1.3438^{* * *}$ & $1.3253^{* * *}$ \\
& $(0.0416)$ & $(0.0609)$ & $(0.0754)$ & $(0.1018)$ \\
GDP Cap $\Delta$ & 1.0030 & 0.9993 & 1.0127 & 1.0082 \\
& $(0.0114)$ & $(0.0161)$ & $(0.0195)$ & $(0.0254)$ \\
Pop $\Delta$ & $4.8389^{* * *}$ & $11.4706^{* * *}$ & $12.2835^{* * *}$ & $19.1816^{* *}$ \\
& $(0.5244)$ & $(0.7663)$ & $(0.9425)$ & $(1.2758)$ \\
Polity & $0.9692^{* *}$ & $0.9658^{*}$ & $0.9511^{* *}$ & 0.9621 \\
& $(0.0142)$ & $(0.0202)$ & $(0.0241)$ & $(0.0307)$ \\
Trade Ratio & 1.0251 & 1.0108 & 1.0279 & $1.1264^{* *}$ \\
& $(0.0266)$ & $(0.0371)$ & $(0.0453)$ & $(0.0563)$ \\
Dip Exchange & 1.0096 & $1.0190^{*}$ & 1.0011 & 1.0022 \\
& $(0.0079)$ & $(0.0112)$ & $(0.0135)$ & $(0.0180)$ \\
\hline AIC & 414.4195 & 306.8568 & 289.2231 & 193.5915 \\
BIC & 427.3253 & 319.7627 & 302.1289 & 206.4974 \\
Log Likelihood & -198.2097 & -144.4284 & -135.6115 & -87.7957 \\
Deviance & 31.6751 & 32.6167 & 35.1614 & 38.2516 \\
Num. obs. & 31 & 31 & 31 & 31 \\
\hline${ }^{* * *} p<0.01,{ }^{* *} p<0.05,{ }^{*} p<0.1$ & & &
\end{tabular}

In terms of model skill, it has relatively tightly clustered estimates and seems to match quite well with the shape of the actual events. Figure 4 and 5 show that the predicted values follow fairly closely with the actual values. Similarly, figure 6 and 7 (the scatter for riots) show that most of the time, the predicted value is tightly clustered around the accuracy line (45 degree line in charts). Anything below the accuracy line shows that the prediction is too high and anything above it shows that the prediction is too low. The scatter in larger numbers is expected due to the scale of the observation. Karachi's predictions are less tightly clustered than Pakistan's, suggesting that data on structural factors may be less useful in that

\footnotetext{
${ }^{1}$ Notes: Results presented in odds-ratios (a 1\% change in the variable changes the count by a factor of $\mathrm{x}$ ); All Independent variables lagged by one year. $\mathrm{N}$ Events is the number of protest events $(90 \%$ correlated with the number of riots)
} 
context due to the state-level of analysis. Regardless, the trend is generally favorable with regards to model fit.
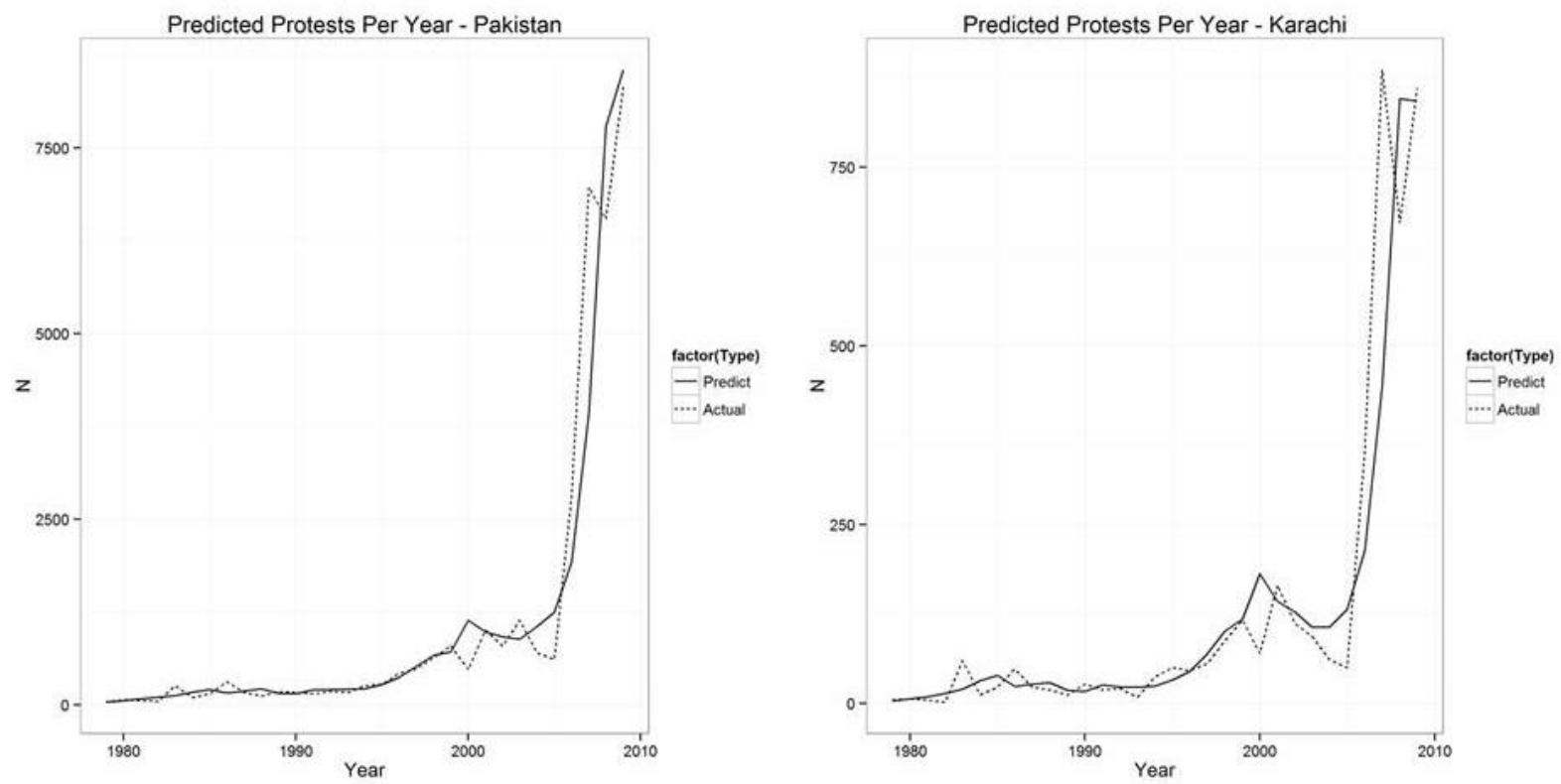

Figure 13 - Predicted Protests per Year
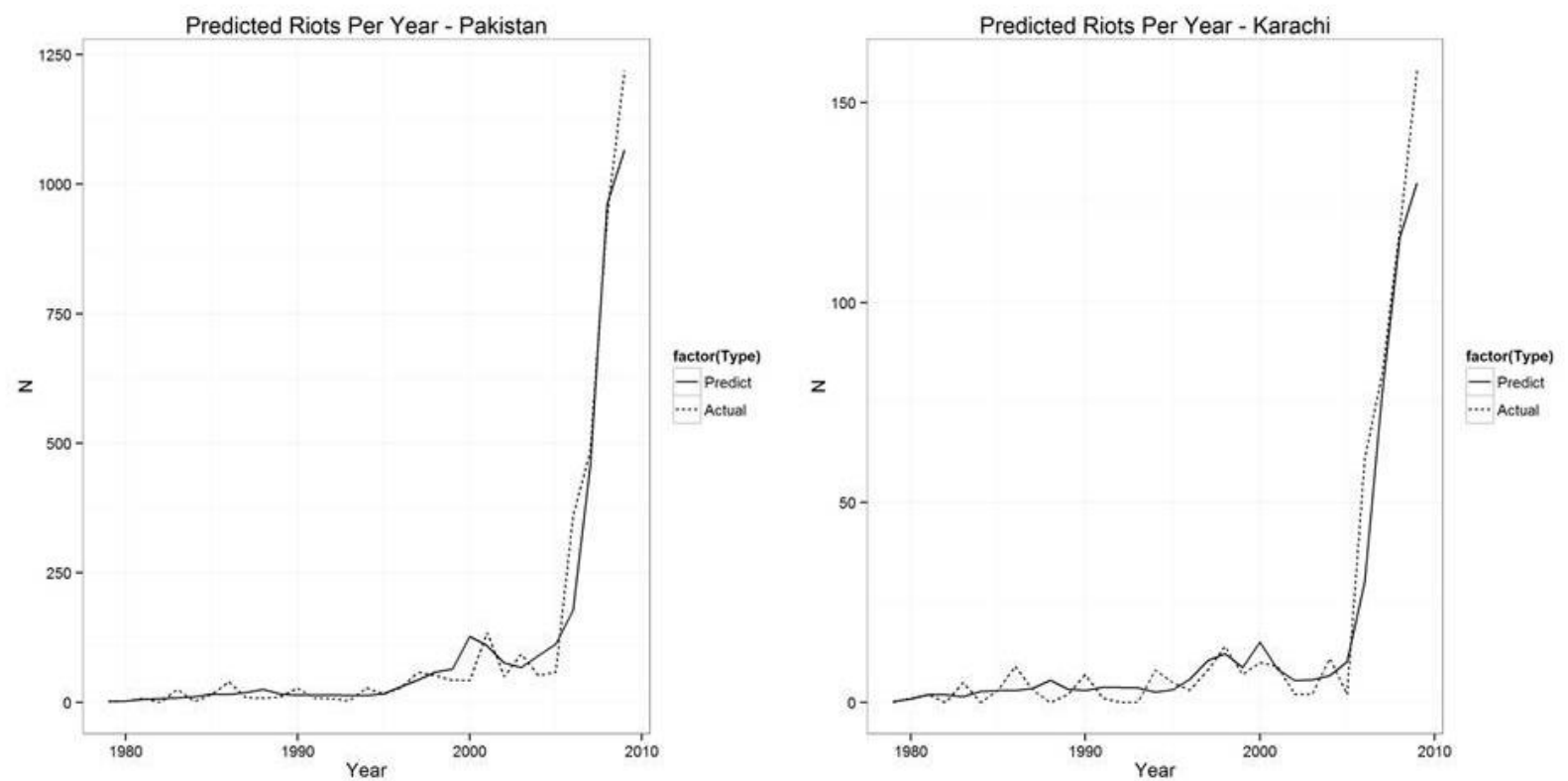

Figure 14 - Predicted Riots per Year 

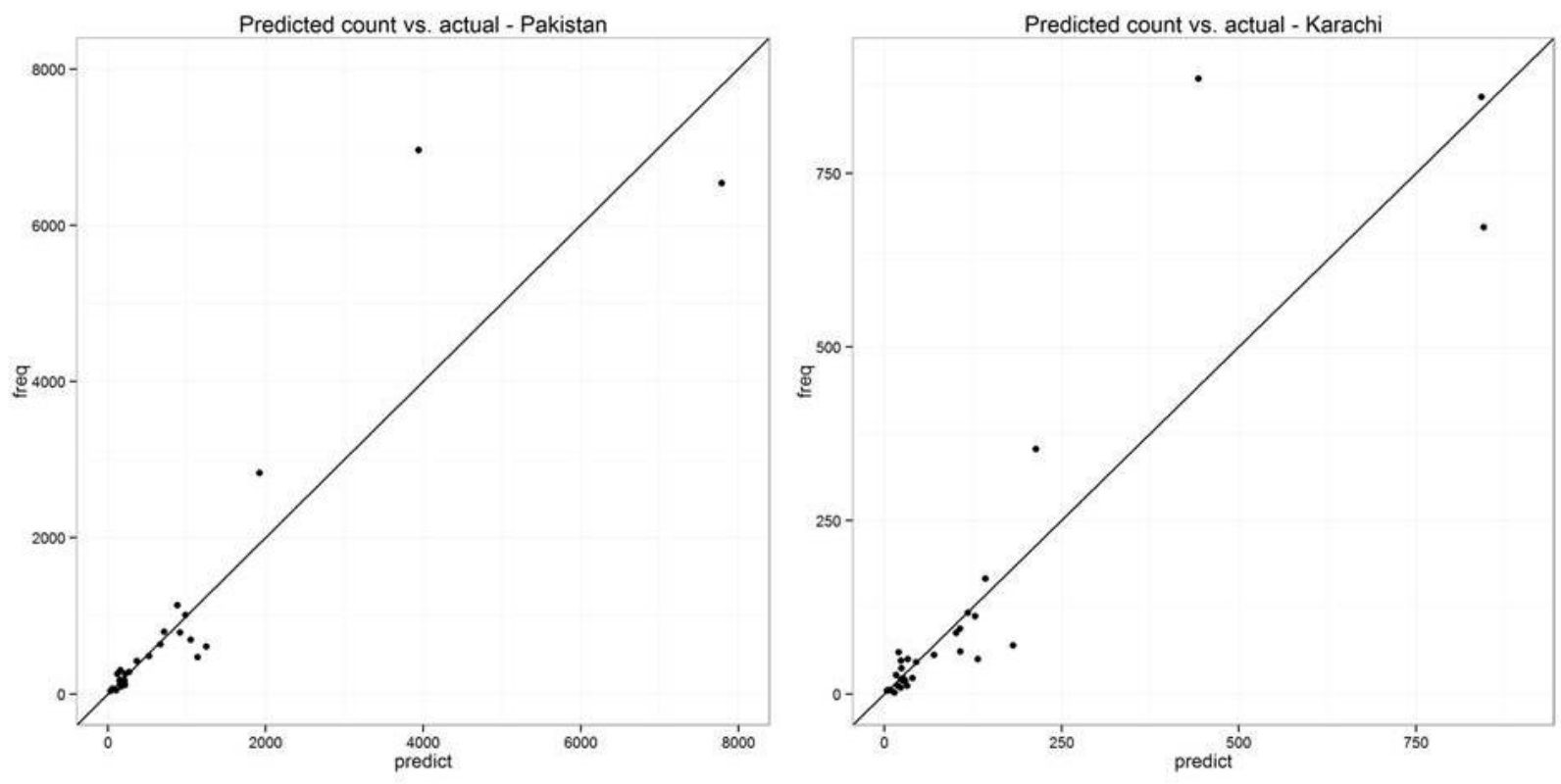

Figure 15 - Predicted Count vs. Actual - Protests
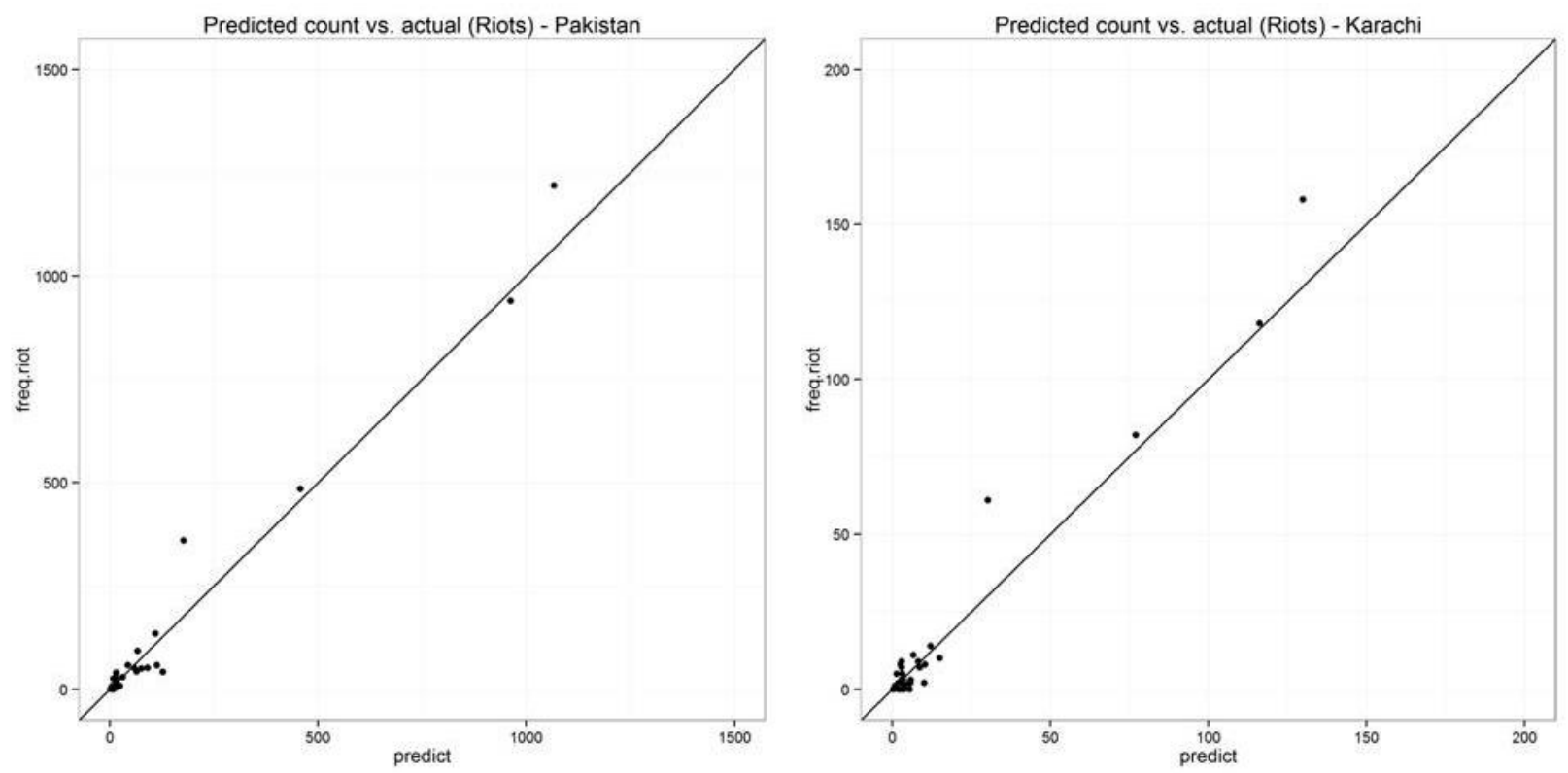

Figure 16 - Predicted Count Vs. Actual - Riots 


\subsection{Works Cited}

Azar, E. (1990). The management of protracted social conflict: theory and cases. Hamphire: Dartmouth Publishing Limited.

Baddeley, M. (2009). Herding, social influence and economic decision-making: socio-psychological and neuroscientific analyses. Philosophical Traditions of the Royal Society B, 365(1538), 281-290.

Barbieri, K., Keshk, O. M., \& Pollins, B. (2009). Trading data: Evaluating our assumptions and coding rules. Conflict Management and Peace Science, 26(5), 471-491.

Bar-Tal, D. (2007). Sociopsychological Foundations of Intractable Conflicts. American Behavioral Scientist, 1430-1453.

Bar-Tal, D. (2009). The Influence of the Ethos of Conflict on Israel Jews' Interpretatino of JewishPalestinian Encounters. Journal or Conflict Resolution, 94-115.

Bayer, R. (2006). Diplomatic Exchange Data Set, v2006.1. Correlates of War.

Bazzi, S., \& Blattman, C. (2011). Economic Shocks and Conflict: The (Absence of?) Evidence from Commodity Prices. Unpublished.

Berenschot, W. (2010). The Spatial Distribution of Riots: Patronage and the Instigation of Communal Violence in Gujarat, India. World Development, 221-230.

Bernauer, T., Bohmelt, T., \& Koubi, V. (2012). Environmental change and violent conflict. Environmental Research Letters, 7, 1-8.

Bollens, S. (1999). Contested Cities: Urban Peacebuilding in Divided Societies. Belfast and Johannesburg. Boulder: Westview.

Box, G. E., \& Draper, N. (1987). Empirical Model Building and Response Surfaces. New York: Wiley and Sons.

Buhaug, H., \& Urdal, H. (2013). An Urbanization Bomb? Population Growth and Social Disorder in Cities. Global Environmental Change, 23(1), 1-10.

Cavanagh, A., \& Dennis, A. (2012). Behind the News: Framing the Riots. Capital \& Class, 275-381.

Coleman, P. T., Vallacher, R. R., Nowak, A., \& Bui-Wrzosinska, L. (n.d.). Intractable Conflict as an Attractor. American Behavioral Scientist.

Collier, P., \& Hoeffler, A. (2004). Greed and Grievance in Civil War. Oxford Economic Papers, 56, 563595.

Collier, P., Hoeffler, A., \& Rohner, D. (2008). Beyond Greed and Grievance: Feasibility and Civil War. Unpublished. 
Cotet, A. M., \& Tsui, K. M. (2010). Oil and Conflict: What Does the Cross-Country Evidence Really Show? Social Science Research Network.

Cramer, C. $(2002,11)$. Homo Economicus Goes to War: Methodological Individualism, Rational Choice and the Political Economy of War. World Development, 30(11).

Crossley, N. (2002). Making sense of social movements. Philadelphia: Open University Press.

Dahl, M., \& Høyland, B. (2012, 0501 ). Peace on quicksand? Challenging the conventional wisdom about economic growth and post-conflict risks. Journal of Peace Research, 49 (3).

Demmers, J. (2012). Theories of Violent Conflict: An Introduction. Hoboken: Taylor and Francis.

Dixon, J. (2009). What Causes Civil Wars? Integrating Quantitative Research Findings. International Studies Review, 11, 707-735.

Doucey, M. (2011). Understanding the Root Caues of Conflicts: Why it Matters for International Crisis Management. International Affairs Review, 2-10.

Douglas, N. (1998). the politics of accomodation, social change and conflict resolution in Northern Ireland. Political Geography, 209-229.

Fearon, J. D. (2005). Primary Commodity Exports and Civil War. The Journal of Conflict Resolution, 49(4), 483-507.

Fearon, J. D., \& Laitin, D. D. (2003). Ethnicity, Insurgency and Civil War. American Political Science Review(1), 75-90.

Fearon, J., Kimulikasara, \& Laitin, D. (2007, 02 01). Ethnic Minority Rule and Civil War Onset. The American Political Science Review, 101(1).

Gleditsch, K. S., \& Ward, M. D. (2012). Forecasting is difficult, especially about the future: Using contentious issues to forecast interstate disputes. Journal of Peace Research, 50(1), 17-31.

Gleditsch, N., Wallensteen, P., Eriksson, M., Sollenberg, M., \& Strand, H. (2002, 09 01). Armed Conflict 1946-2001: A New Dataset. Journal of Peace Research, 39(5).

Gray, B., Coleman, P. T., \& Putnam, L. L. (2007). Intractable Conflict: New Perspectives on the Causes and Conditions for Change. American Behavioral Scientist, 1415-1429.

Gross, M. (2011). Why do People Riot? Current Biology, 673-76.

Gurr, T. (1970). Why Men Rebel. New Jersey: Princeton University Press.

Hadjipavlou, M. (2007). The Cyprus Conflict: Root Causes and Implications for Peacebuilding. Journal of Peace Research, 349-365.

Hansen, W., Ramsbotham, O., \& Woodhouse, T. (2001). Hawks and Doves: Peacekeeping and Conflict Resolution. Berlin: Berghof Research Center for Constructive Conflict Management. 
Hirshleifer, J. (1995). Theorizing About Conflict. Los Angeles: UCLA Department of Economics.

Hochrainer, S. (2009). Assessing the Macroeconomic Impacts of Natural Disasters: Are there any? Sustainable Development Network Vice Presidency, Global Facility for Disaster Reduction and Recovery Unit. New York: World Bank.

Horowitz, D. L. (1985). Ethnic Groups in Conflict. Berkeley and Los Angeles: University of California Press, Ltd.

IFPRI. (2013, January 1). Middle East and North Africa: Our Work. Retrieved March 8, 2013, from International Food Policy Research Institute: http://www.ifpri.org/book6959/ourwork/researcharea/middle-east-and-north-africa

Kahl, C. (2006). States, Scarcity, and Civil Strife In The Developing World. Princeton and Oxford: Princeton University Press.

Kurzrok, A. J. (2013). Elastic Futures: Global Trends, Science and Technology - A Project of the Pacific Northwest National Laboratory's Center for Global Security. Richland: Pacific Northwest National Laboratory, Center for Global Security.

Leetaru, K., \& Schrodt, P. A. (2013). GDELT: Global Data on Events, Location and Tone, 1979-2012. Proceedings of the International Studies Association Meetings. San Fransisco: International Studies Association.

Leventis, E. C., \& Tsokkalides, A. (2007). Protracted Social Conflict Analysis and Cyprus: An Assessment. The Cyprus Review, 31-49.

Lewis, P., \& Newburn, T. (2011, December 4). The Reading the Riots Project: Our Methodology Explained. The Guardian.

Liotta, P., \& Miskel, J. F. (2012). The Real Population Bomb: Megacities, Global Security and the Map of the Future. Dulles: Potomac Books.

Marshall, M. G., \& Gurr, T. R. (2010). Polity IV Project: Political Regime Characteristics and Transitions. Polity IV Project.

Messer, E. (2009). RISING FOOD PRICES, SOCIAL MOBILIZATIONS, AND VIOLENCE: CONCEPTUAL ISSUES IN UNDERSTANDING AND RESPONDING TO THE CONNECTIONS LINKING HUNGER AND CONFLICT. NAPA Bulletin, 32(1).

Meyer, D. S. (2004). Protest and Political Opportunities. Annual Review of Sociology, 30, 125-145.

Miall, H. (2004). Conflict Transformation. Berghof Research Center for Constructive Conflict Management, 1-18.

Milanovic, B., \& Squire, L. (2005). Does tariff liberalization increase wage inequality? Some empirical evidence. National Bureau of Economic Research. 
Moss, R. H., Brenkert, A., \& Malone, E. L. (2001). Vulnerability to Climate Change: A Quantitative Approach. Richland, WA: Pacific Northwest National Laboratory.

Moss, R., Babiker, M., Brinkman, S., \& Calvo, E. (2008). Towards New Scenarios for Analysis of Emissions, Climate Change, Impacts, and Response Strategies: IPCC Expert Meeting Report Technical Summary. Geneva: Intergovernmental Panel on Climate Change.

Musallam, N., Coleman, P. T., \& Nowak, A. (2007). Understanding the Spread of Malignant Conflict: A Dynamcial Systems Perspective. Columbia University Journal Article, 1-35.

National Intelligence Council. (2013). Global Trends 2030: Alternative Worlds. Washington, D.C.: National Intelligence Council.

NIC. (2013). Global Trends 2030: Alternative Worlds. Washington, D.C.: National Intelligence Council.

Oliver, P. E., Cadena-Roa, J., \& Strawn, K. D. (2003). Emerging Trends in the Study of Protest and Social Movements. Research in Political Sociology, 11.

Olson, J. (2013). Food Fight: The Effect of Food Availability on the Probability of Violent Conflict Onset. School of Public Policy. Corvallis: Oregon State University.

Olson, M. (1965). The Logic of Collective Action. Cambridge: Harvard University Press.

Opp, K.-D., \& Kittel, B. (2010). The Dynamics of Political Protest: Feedback Effects and Interdependence in the Explanation of Protest Participation. European Sociological Review, 26(1), 97-109.

Patel, R., \& McMichael, P. (2009). A Political Economy of the Food Riot. Review, XXXII(1), 9-35.

Pfaffenberger, B. (1994). The Structure of Protracted Conflict: The Case of Sri Lanka. Humbolt Journal of Social Relations, 121-44.

Philips, R., Frost, D., \& Singelton, A. (2013). Researching the Riots. The Geographical Journal, 3-10.

Pinstrup-Andersen, P., \& Shimokawa, S. $(2008,12)$. Do poverty and poor health and nutrition increase the risk of armed conflict onset? Food Policy, 33(6).

Piya, L. (2009). Protracted People's War in Nepal: An Analysis from the Perspective of Azar's Theory of Protracted Social Conflict. Journal of International Development and Cooperation, 185-203.

Raafat, R. M., Chater, N., \& Frith, C. (2009). Herding in Humans. Trends in Cognitive Sciences, 420-24.

Rakodi, C. (2012). Inter-Religious Violence and its Aftermath: Insights from Indian and Nigerian Cities. Journal of Asian and African Studies, 1-16.

Ramsbotham, O. (2005). The Anaylsis of Protracted Social Conflict: A Tribute to Edward Azar. Review of International Studies, 109-25. 
Rayner, S., Lach, D., \& Ingram, H. (2005). Weather Forecasts Are for Wimps*: Why Water Resource Managers Do Not Use Climate Forecasts. Climatic Change, 69, 197-227.

Ropers, N. (2008). Systemic Conflict Transformation: Reflections on the Conflict and Peace Process in Sri Lanka. Berlin: Berghof Research Center for Constructive Conflict Management.

Ross, M. (2004, 05 01). What Do We Know about Natural Resources and Civil War? Journal of Peace Research, 41(3).

Rothman, J., \& Olson, M. L. (2001). From Interests to Identities: Towards a New Emphasis in Interactive Conflict Resolution. Journal of Peace Research, 289-205.

Ryan, Y. (2011, January 26). How Tunisia's revolution began. Al Jazeera.

Steinbruner, J. D., Stern, P. C., \& Husbands, J. L. (2013). Climate and Social Stress: Implications for Security Analysis. Washington, D.C.: National Academies Press.

Taleb, N. N. (2007). The Black Swan: The Impact of the Highly Improbable. New York: Random House.

Till, J. (2012). The Broken Middle: The Space of the London Riots. Cities, 1-4.

Tilly, C. (1978). From Mobilization to Revolution. Reading, MA: Addison-Wesley.

Unwin, S. D., Moss, R., Rice, J., \& Scott, M. (2011). Characterizing Uncertainty for Regional Climate Change Mitigation and Adaptation Decisions. Richland: Pacific Northwest National Laboratory.

Woolridge, J. M. (2009). Introductory Econometrics: A Modern Approach (4 ed.). Mason: South-Western Cengage Learning.

World Bank. (2013, August 7). Global development finance database. World Bank.

Zartman, W. (2005). Analyzing Intractability. In C. Crocker, F. O. Hampson, \& P. Aall, Grasping the Nettle: Analyzing cases of intractable conflict. Washington, D.C.: Institute of Peace Press. 


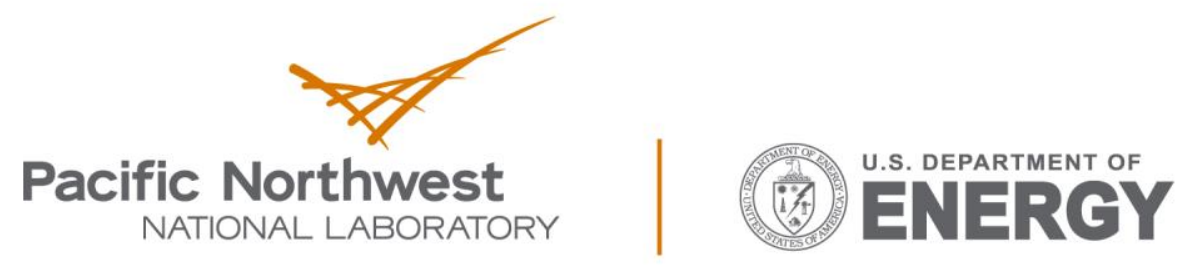

Proudly Operated by Battelle Since 1965

902 Battelle Boulevard

P.O. Box 999

Richland, WA 99352

1-888-375-PNNL (7665)

www.pnnl.gov 